Linköping Studies in Science and Technology

Dissertation No. 1788

\title{
Study of GaN Based Nanostructures and Hybrids
}

\author{
Mathias Forsberg
}

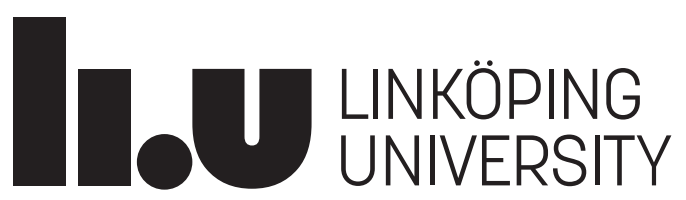

Thin Film Physics Division

Department of Physics, Chemistry, and Biology (IFM)

Linköping University, SE-581 83 Linköping, Sweden

Linköping 2016 
The cover of this thesis depicts (with an artists interpretation) a gallium target with the characteristic pink/purple nitrogen-plasma reaching, from the target below, to the sample holder above. Digitally drawn by Mathias Forsberg 2016

During the course of research underlying this thesis, Mathias Forsberg was enrolled in Agora Materiae, a multidiciplinary doctoral program at Linköping University, Sweden.

(C) Mathias Forsberg

ISBN 978-91-7685-692-5

ISSN 0345-7524

Printed by LiU-Tryck 2016

Copyright(C) all rights reserved 
Kunskap äger $i$ sig självt sitt eget syfte 



Abstract

$\mathrm{GaN}$ and its alloys with $\mathrm{Al}$ and In belong to the group III nitride semiconductors and are today the materials of choice for efficient white light emitting diodes (LEDs) enabling energy saving solid state lighting. Currently, there is a great interest in the development of novel inexpensive techniques to fabricate hybrid LEDs combining high quality III-N quantum well (QW) structures with inexpensive colloidal nanoparticles or conjugated polymers. Such hybrid devices are promising for future micro-light sources in full-color displays, sensors and imaging systems. Organics can be engineered to emit at different wavelengths or even white light based on functional groups or by blend of several polymers. This is especially important for the green region, where there is still a lack of efficient LEDs. Besides optoelectronics, other applications such as biochemical sensors or systems for water splitting can be realized using GaN-based nanostructures. Despite a significant progress in the field, there is still a need in fundamental understanding of many problems and phenomena in III-nitride based nanostructures and hybrids to fully utilize material properties on demand of specific applications.

In this thesis, hybrid structures based on AlGaN/GaN QWs and colloidal $\mathrm{ZnO}$ nano-crystals have been fabricated for down conversion of the QW emission utilizing non-radiative (Förster) resonant energy transfer. Time-resolved photoluminescence (TRPL) was used to investigate the QW exciton dynamics depending on the cap layer thickness in the bare QW and in the hybrid samples. Although the surface potential influences the exciton dynamics, the maximum pumping efficiency assuming a non-radiative energy transfer mechanism was estimated to be $\sim 40 \%$ at $60 \mathrm{~K}$ in the structure with thin cap layer of $3 \mathrm{~nm}$. 
Since bulk GaN of large area is difficult to synthesize, there is a lack of native substrates. Thus, GaN-based structures are usually grown on SiC or sapphire, which results in high threading dislocation density in the active layer of the device and can be the reason of efficiency droop in GaN based LED structures. Fabricating GaN nanorods (NR) can be a way to produce GaN with lower defect density since threading dislocations can be annihilated toward the NR wall during growth. Here, GaN(0001) NRs grown on $\mathrm{Si}(111)$ substrates by magnetron sputtering using a liquid Ga target have been investigated. A high quality of NRs have been confirmed by transmission electron microscopy (TEM) and TRPL. Two strong near band gap emission lines at $\sim 3.42 \mathrm{eV}$ and $\sim 3.47 \mathrm{eV}$ related to basal plane stacking faults $(\mathrm{SF})$ and donor-bound exciton (DBE), respectively, have been observed at low temperatures. TRPL properties of the SF PL line suggest that SFs form a regular structure similar to a multiple QWs, which was confirmed by TEM. The SF related PL measured at $5 \mathrm{~K}$ for a single NR has a significantly different polarization response compared to the GaN exciton line and is much stronger polarized $(>40 \%)$ in the direction perpendicular to the NR growth axis.

Hybrids fabricated using GaN NRs and the green emitting polyfluorene $(\mathrm{F} 8 \mathrm{BT})$ have been studied using micro-TRPL. In contrast to the DBE emission, the recombination time of the SF-related emission was observed to decrease, which might be due to the Förster resonance energy transfer mechanism.

Compared to chemical vapor deposition, sputtering allows synthesis at much lower temperatures. Here, sputtering was employed to grow In$\mathrm{AlN} / \mathrm{GaN}$ heterostructures with an indium content targeted to $18 \%$, which is lattice matched to GaN. This means that near strain-free GaN films can be synthesized. It was found that using a lower temperature $(\sim 25$ ${ }^{\circ} \mathrm{C}$ ) while depositing the top InAlN results in an improved interface quality compared to deposition at $700{ }^{\circ} \mathrm{C}$. In latter case, regions of quaternary alloy of InAlGaN forming structural micro-defects have been observed at the top InAlN/GaN interface in addition to optically active flower-like defect formations. 


\section{Populärvetenskaplig sammanfattning}

Belysning kräver stora mängder energi. Det uppskattades 2010 att belysning bara i Sverige förbrukade omkring 14 TWh per år. För att minska energiförbrukningen är det därför viktigt att utveckla nya och mer energieffektiva alternativ till de traditionella glödlamporna. Ett sådant alternativ är vita lysdioder, även kallad LED (från engelskans light emitting diode) och idag ersätts glödlamporna i allt högre grad av energieffektiva LED lampor. Upptäckterna som gjorde det möjligt belönades med Nobelpriset 2014 som gick till Isamu Akasaki, Hiroshi Amano och Shuji Nakamura för deras arbete att utveckla galliumnitrid $(\mathrm{GaN})$.

$\mathrm{GaN}$ och dess legeringar med indium (In) och aluminium ( $\mathrm{Al}$ ) brukar benämnas nitrider och är halvledare. Vad som är unikt med halvledare är att man kan kontrollera materialets elektriska konduktivitet genom så kallad dopning. När man dopar tillsätter man små mängder föroreningar, så kallade störämnen. Störämnet kan antigen bidra med extra elektroner (donatorer) eller binda elektroner (acceptorer) till sig. Om en elektron binds uppstår det en avsaknad av en elektron. Avsaknaden, eller hålet som den vanligen benämns, är rörlig i kristallen och om ett hål och en elektron möts rekombinerar dem och energi frigörs genom att utsända ljus eller skapa vibrationer hos omgivande atomer. Hur mycket energi som frigörs beror på materialets så kallade bandgap. Olika energier på ljuset motsvarar olika färger, och i fallet GaN som har ett bandgap på $3.4 \mathrm{eV}$ får vi ett ultraviolett (UV) ljus. Genom att legera $\mathrm{GaN}$ med In eller $\mathrm{Al}$ kan vi ändra bandgapet från $0.78 \mathrm{eV}(\mathrm{InN})$ till $6.2 \mathrm{eV}(\mathrm{AlN})$ vilket motsvarar ljusets våglängd från infrarött (IR) till UV, d.v.s. över hela det synliga området.

För att skapa vitt ljus krävs det en blandning av våglängder. Dagens nitrid-baserade LED-lampor fungerar delvis på samma sätt som lysrör där 
en fosfor omvandlar ultraviolett-blått ljus till vitt. Det vita ljuset skapas genom att blanda det blå-violetta ljuset från dioden med gult ljus från fosforn. Med dagens omvandlingsteknik förlorar vi dock mycket energi och därför finns det utrymme för att ytterligare förbättra energieffektiviteten på GaN baserade-LED.

En teknik som kan leda till nya energieffektivare och billigare LEDs i framtiden är komponenter baserade på hybridstrukturer. En hybridstruktur består av olika föreningar där vanligen en av dem är oorganisk och den andra organisk. Tanken är att man ska tillvarata de bästa egenskaperna från respektive förening. Som ljusproducerande material (ljuskälla) kan man t.ex. använda en oorganisk halvledare som GaN som har en bättre ledningsförmåga och kvantverkningsgrad än organiska halvledare och för att ändra ljusets våglängd till den färg man önskar kan man använda en organisk halvledare som är billig och lätt att syntetisera (våglängdsomvandlingsskikt).

GaN-baserade komponentstrukturer består av tunna filmer med tjocklekar som mäts i nanometer (miljondels millimeter) ovanpå andra kristallina material. När tjockleken är så pass tunn skiljer sig materialets egenskaper avsevärt från samma material i bulk. För industriell framställning av GaN används oftast s.k. CVD (från engelskans chemical vapor deposition). Där tillåts gaser reagera i höga temperaturer ovanför en substratyta för att producera filmen. En alternativ metod är s.k. förstoftning eller sputtring. Man låter då joner kollidera med en katod och på så sätt slå ut katodmaterial som kan fångas upp på en substratyta för att producera filmen. Fördelarna med detta framför CVD är att metoden inte är lika begränsad med avseende på vilka material som kan tillverkas samt att filmer kan beläggas vid lägre temperaturer och utan miljöfarliga gaser.

Denna avhandling fokuserar på syntes och karaktärisering av olika nitrider samt studerar möjligheter och begränsningar hos hybrida strukturer baserade på GaN-baserade komponenter. Syntes av tunna filmer har genomförts med metoden förstoftning av rena metalliska katoder och kvävgas. Karaktärisering av prover syntetiserade med CVD och nanostavar syntetiserade med förstoftning har också genomförts. Karaktäriseringsmetoder som använts under denna studie har varit optisk spektroskopi i form av fotoluminescens och katodoluminescens. Mikroskopiska tekniker i form av transmissionselektronmikroskop, svepelektronmikroskop och traditionella optiska mikroskop har även använts. För ytterligare strukturell karaktärisering har även röntgendiffraktion utnyttjats.

Mina resultat visar hur hybrida strukturer kan produceras med olika material-konstellationer. Resultaten tyder på en maximal verkningsgrad 
för överföring av energi mellan ljuskällan - våglängdsomvandlingsskiktet på $\sim 40 \%$ i dessa hybrider. Gränsytan mellan ljuskällan och våglängdsomvandlingsskiktet har visats vara en mycket kritisk begränsning om den inte kontrolleras noggrant. Den höga kvalité på materialet som krävs för lysdioder var svårt att uppnå med förstoftning som syntesmetod av filmer. Problem uppkommer främst när filmer av olika nitridlegeringar staplas på varandra. Ett exempel är att atomer diffunderar mellan de olika filmerna. Ett förslag på mekanism bakom detta har presenterats och därmed har även en lösning på problemet kunnat implementeras. Spektroskopiska studier av GaN-baserade nanostavar visar hur de idag kan syntetiseras med högre kvalité än filmer som växt med samma metod. Nanostavar har påträffats som uppvisade luminescens relaterad till staplingsfel, d.v.s. hur atomerna i kristallen bröt kristallordningen. Denna luminescens har även konstaterats avge polariserat ljus. Dessa nanostavar användes även som oorganisk komponent $\mathrm{i}$ en hybridstruktur. I och med detta kunde det framläggas bevis för att staplingsfel som ljuskälla hade en starkare växelverkan med våglängdsomvandlings-materialet än andra delar av nanostaven. 

This doctoral thesis summarizes my work at Linköping University at the Department of Physics, Chemistry and Biology (IFM) within the thin film physics division from May 2012 to November 2016. My PhD studies are built on my licentiate studies. The aim of this thesis is to study optical and structural properties of GaN based nano and hybrid structures. The thesis contains 6 scientific paper, either in the form of published papers in scientific journals, or as manuscripts submitted or in final preparation for submission to scientific journals. This is preceded by 6 chapters giving the reader an introduction to the field. The project was financed by the Swedish Energy Agency, by CeNano, by the Swedish Research Council (VR), by the Swedish Government Strategic Research Area in Materials Science on Functional Materials (AFM), by Carl Trygger's foundation and by Angpanneföreningen $(\AA \mathrm{F})$ and I appreciate this support.

Linköping 2016 


\section{Included publications}

I Dynamic properties of excitons in $\mathrm{ZnO} / \mathrm{AlGaN} / \mathrm{GaN}$ hybrid nanostructures

Scientific Reports 5 : 7889 (2015)

M. Forsberg, C. Hemmingsson, H. Amano, G. Pozina

I took part in the planning, performed the spin-coating $(\mathrm{ZnO})$, performed part of the characterization (TRPL), took part in the discussion of the results and wrote the first version of the manuscript

II Time-resolved photoluminescence properties of hybrids based on inorganic $\mathrm{AlGaN} / \mathrm{GaN}$ quantum wells and colloidal $\mathrm{ZnO}$ nanocrystals Superlattices and Microstructures 87, 38-41 (2015)

M. Forsberg, C. Hemmingsson, H. Amano, G. Pozina

I performed part of the characterization (TRPL), took part in the discussion of the results and wrote the first version of the manuscript

III Stacking fault related luminescence in GaN nanorods Nanotechnology 26, 355203 (2015)

M. Forsberg, E. A. Serban, I. Poenaru, C.-L. Hsiao, M. Junaid, J. Birch and G. Pozina

I took part in the planning, performed part of the characterization (TRPL, CL, SEM). I performed the TEM sample preparation, took part in the discussion of the results and wrote the first version of the manuscript

IV Polarization of stacking fault related luminescence in GaN nanorods Submitted for publication in Applied Physics Letters

G. Pozina, M. Forsberg, E. A. Serban, C.-L. Hsiao, M. Junaid, J. Birch

I performed the SEM and XRD characterization, performed some of the TRPL experiments and took part in the discussion of the manuscript 
$\mathrm{V}$ Near band gap luminescence in hybrid organic-inorganic structures based on sputtered GaN nanorods

Manuscript in final preparation

M. Forsberg, E. A. Serban, C.-L. Hsiao, M. Junaid, J. Birch, G. Pozina

I planned the study, performed the spin-coating of F8BT, performed the sample preparation before experiment, performed the experiment (TRPL), took part in discussion of the results and wrote the first version of the manuscript

VI InAlGaN regions and flower-like formations in GaN films from DCmagnetron sputtered $\operatorname{In}_{\mathrm{x}} \mathrm{Al}_{1-\mathrm{x}} \mathrm{N} / \mathrm{GaN}$ heterostructures

Submitted for publication in Thin Solid Films

M. Forsberg, J. Lu, C.-L. Hsiao, J. Birch, G. Pozina

I planned the study, performed all depositions (sputtering), performed the SEM and CL characterizations, performed the sample preparation for TEM, took part in the TEM and EDX characterization, took part in the discussion of the results and wrote the first version of the manuscript 


\section{Related publications not included in this thesis}

I $\mathrm{Ga}_{2} \mathrm{O}_{3}$ nano-flakes emission properties Submitted for publication in Scientific Reports

G. Pozina, M. Forsberg, M. A. Kaliteevski, and C. Hemmingsson

\section{Conference presentations}

I Investigation of hybrid structures based on III-Nitrides M. Forsberg, H. Amano, L. Hultman, G. Pozina

European Materials Research Society (E-MRS) spring meeting May 27 (2013), Strasbourg, France, Oral

II III-N quantum well structures for non-radiative energy transfer studies

M. Forsberg, C.-L. Hsiao, G. Pozina

Advanced Functional Material (AFM) (through Agora Materiae) August 20 (2014), Kolmården, Sweden, Poster

III Properties of Stacking Faults in Magnetron Sputtered GaN Nanorods M. Forsberg, E. A. Serban, I. Poenaru, C.-L. Hsiao, M. Junaid, J. Birch and G. Pozina

$4^{\text {th }}$ Magnetron, Ion processing \& Arc Technologies European Conference (MIATEC) December 8 (2015), Paris, France, Oral, Michel Cantarel grant recipient for best presentation

IV Optical studies of hybrid structures based on $\mathrm{ZnO}$ nanocrystals and AlGaN/GaN QW

M. Forsberg, C. Hemmingsson, H. Amano, G. Pozina

Advanced Functional Materials (AFM) (through Agora Materiae) August 23 (2016), Kolmården, Sweden, Poster 
I would like to thank everyone who helped me with my $\mathrm{PhD}$ studies at $\mathrm{LiU}$

- In particular: My supervisor Associate Professor Galia Pozina: Thank you very much for your excellent supervision and support in my progress. I highly admire your skill and scientific knowledge within the field and I appreciate your dedication to help me.

- My co-supervisor Dr. Ching-Lien Hsiao: Thank you for all your help over the years, especially in teaching me the deposition systems which I am forever grateful of.

- Professor Jens Birch and Professor Lars Hultman: I am grateful to have been a part of the thin film physics division and you are both good role models for every student here.

- Co-authors; Alexandra Serban, Iuliana Poenaru, Dr. Mohammad Junaid, Dr. Jun Lu, Dr. Mihail Kaliteevski, Docent Carl Hemmingsson and Professor Hiroshi Amano: Thank you, it has been a pleasure!

- Thomas Lingefeldt and Harri Savimäki: Thank you for all the times you have resolved the issues with equipment and instruments making my experiments and characterizations run smoothly.

- To all the others who helped me understand and fix the deposition systems; Dr. Agne Žukauskaité and Dr. Per Sandström, thank you very much. - Thank you all within the "9 O'clock fika club" and the lunch-group for interesting discussions

- And to everyone in the Thin Film Physics Division and Agora Materiae, thank you all. 
- A special thanks to everyone who helped me work out during these years; Daniel, Sit, Sebastian, Aylin, Isabella, Fei, Peter, Rickard, Thomas, Nina, Julien, Joseph, Mitsu. Because health is important, but not as important as gains.

My family:

- My parents Patric and Gunnel, thanks for teaching me to think and allow me this mind.

- Thanks to Andreas, for a man's back is always vulnerable, unless he has a brother 
1 Introduction 1

1.1 Hybrid structures . . . . . . . . . . . . . . . . . . . 3

1.2 Research objectives ................ . . 4

2 Group III-Nitrides $\quad 5$

2.1 Ternary group III-nitrides . . . . . . . . . . . 8

3 Optical Properties of Semiconductors 11

3.1 Förster resonance energy transfer . . . . . . . . . 16

4 Thin Film Deposition 19

4.1 Vacuum science . . . . . . . . . . . . . . . . . 20

4.2 Sputter deposition ................... 23

4.2.1 Growth modes ................ . 24

4.2.2 Reactive sputtering. . . . . . . . . . . 26

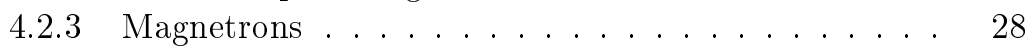

4.2.4 The reactors ............... . . 30

4.2.5 InAlN/GaN/InAlN heterostructure growth . . . . . 33

4.3 Metal-organic chemical vapor deposition . . . . . . . . . 34

4.3.1 Hot wall vs cold wall . . . . . . . . . . . 36

4.3.2 Growth rate.............. 36

5 Characterization $\quad 39$

5.1 X-ray diffraction . . . . . . . . . . . . . . 39

5.2 Scanning electron microscopy . . . . . . . . . . . . . . . . 41

5.3 Transmission electron microscopy . . . . . . . . . . 43 
5.4 Cathodoluminescence . . . . . . . . . . . . . . . . . 43

5.5 Photoluminescence . . . . . . . . . . . . . . . 46

5.5.1 Time-resolved photoluminescence (TRPL) . . . . . 46

5.5.2 Micro time-resolved photoluminescence ( $\mu$-TRPL) $\quad . \quad 47$

6 Scientific Contriubtions 49

6.1 Paper I . . . . . . . . . . . . . . . . . . . . . 49

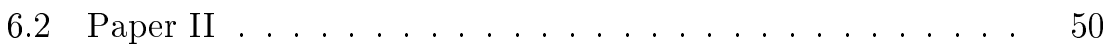

6.3 Paper III ...................... 50

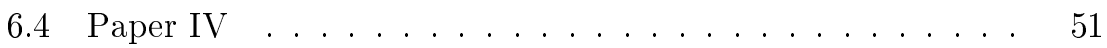

6.5 Paper V . . . . . . . . . . . . . . . . . . . 51

6.6 Paper VI . . . . . . . . . . . . . . . 52

$\begin{array}{ll}\text { Paper I } & 59\end{array}$

$\begin{array}{ll}\text { Paper II } & 67\end{array}$

$\begin{array}{ll}\text { Paper III } & 73\end{array}$

$\begin{array}{ll}\text { Paper IV } & 85\end{array}$

$\begin{array}{ll}\text { Paper V } & 99\end{array}$

$\begin{array}{ll}\text { Paper VI } & 115\end{array}$ 


\section{CHAPTER 1}

\section{Introduction}

The semiconductor technology has paved way for the rapid development of electronics, which have given us computers and cellular phones, the cornerstones in the creation of the modern information society. During the last decade, the semiconductors of group III-nitrides ( $\mathrm{GaN}$ and its alloys with In and $\mathrm{Al}$ ) have revolutionized the laser and light-emitting diodes (LED) market due to their ability to emit a wide range of wavelengths from infrared (IR) to ultra violet (UV) and today, energy efficient solidstate lighting based on the III-nitrides is replacing traditional incandescent bulbs. The development of the group-III-nitride based devices was awarded in 2014, when Isamu Akasaki, Hiroshi Amano and Shuji Nakamura received the Nobel Prize in physics for their work on the GaN based blue LED. The following physical properties of $\mathrm{GaN}$ such as the direct wide band gap of $3.4 \mathrm{eV}$ at room temperature, high electron mobility and high breakdown voltage has attracted a lot of attention. Additionally, by alloying GaN with In or $\mathrm{Al}$, the band gap can be varied in a broad range from $0.8 \mathrm{eV}$ up to 6.2 $\mathrm{eV}$. Due to these outstanding properties, there is a high research activity in the field, which can be exemplified, for instance, by a bibliometric search in Web of science ${ }^{T M}$ revealing how the number of publications per year on GaN has steadily increased from around 20 in 1986 to over 3000 in 2015.

The most common semiconductors such as silicon and GaAs can be grown from a melt for production of native substrates, however, this is not possible for $\mathrm{GaN}$ at reasonable temperatures and pressures $^{1}$ and due to this, the development of the GaN technology has been hampered for many 
years. In order to overcome this obstacle, different techniques using foreign substrates such as $\mathrm{Si}, \mathrm{SiC}$ or sapphire has been developed. However, growth on foreign substrate creates numerous defects limiting the performance of devices; therefore, there is a high activity going on in order to improve the material for industrial needs. Techniques such as metalorganic chemical vapor deposition (MOCVD) ${ }^{2}$ and molecular beam epitaxy $(\mathrm{MBE})^{3}$ are commonly used for growth of device structures, while halide vapor phase epitaxy $^{4-6}$, high pressure solution growth $(\mathrm{HPS})^{7,8}$, sodium (Na) flux ${ }^{9,10}$, and the ammonothermal method ${ }^{11}$ are developed for growth of thick crystals for substrate production.

In this thesis, one of the tasks was to study and develop growth of GaN by sputtering from a liquid pure gallium target in a nitrogen and/or argon atmosphere. To this date, only few studies have considered this approach ${ }^{12}$. An alternative way to produce $\mathrm{GaN}$ by sputtering is deposition of $\mathrm{Ga}_{2} \mathrm{O}_{3}$ followed by ammonization ${ }^{13,14}$. For the thin film growth, the choice of substrates is important in order to obtain high quality crystals. As aforementioned, the lack of low cost high quality GaN substrates of large areas requires commercial devices to be grown on e.g. $\mathrm{Si}, \mathrm{SiC}$ or sapphire. Due to the huge lattice mismatch between GaN and the substrate materials, threading dislocations of high density in the range of $10^{11}-10^{12} \mathrm{~cm}^{-2}$ are introduced in the epitaxial structure, which lowers drastically the device efficiency. However, the defect density in the active layer can be significantly reduced by employing an additional buffer layer (AlN, or low temperature $\mathrm{GaN}$ ) on sapphire before depositing the GaN based structure, as was found by Akasaki and Amano, who also invented an efficient p-type doping in $\mathrm{GaN}^{15,16}$. Today, however, dislocation densities in III-nitride epitaxial structures are still high to affect negatively the device performance ${ }^{17,18}$. The problem can be overcome, for example, by growing GaN nanorods (NR). In this case, threading dislocations can be annihilated at the NR sides $^{19,20}$, which gives rise to GaN nanostructures of high crystal quality. Additionally, these types of nanostructures can be grown on substrates with even higher lattice mismatch, which enables the use of the mature and cheaper substrates, e.g. silicon.

Another group III-nitride studied in the thesis is InAlN. InAlN with an indium composition of $\sim 18 \%$ can be lattice matched to GaN according to Vegard's law. Unfortunately, at this composition InAlN is not stable due to a considerable difference in bond length and optimal growth temperature between InN and AlN. A significant advantage with sputtering is that InAlN can be grown by this technique as metastable alloy. The development of InAlN thin film growth is relatively new compared to GaN. It started in 
1981 when Starosta reported on sputtered $\operatorname{InAlN}^{21}$. Since then, although the full composition range has been grown ${ }^{22}$, the understanding of InAlN structural and electrical properties are still scarce.

\subsection{Hybrid structures}

Full-colour (red-, green-, blue-) and white-light emission sources are required for many optoelectronic applications. The most common way of achieving visible lighting is down conversion of blue and UV luminescence when a GaN-based LED pumps a phosphor that generates secondary (longer wavelength) fluorescence. As the light emitting elements in modern micro-LED arrays become smaller, phosphors (usually rare earth doped metal oxide crystals) is still a limiting size factor ${ }^{23}$. However, parallel to the development of nitride materials and devices, a huge progress has been made in organic materials such as conjugated polyfluorenes and nanocrystals emitting in visible region ${ }^{24,25}$. These low-cost materials can be easily processed and can be engineered to emit at different wavelengths ${ }^{26,27}$.

Hybrid light-emitting devices based on the synergistic combination of III-nitride and organics or colloidal nanocrystals possess a combination of the attractive electrical properties of inorganic materials and the high fluorescence yields across the visible spectrum that are typical for polyfluorenes or colloidal nanopcrystals. In a conventional class of hybrids the UV luminescence from the GaN-based LED down converts to visible light in the polymers or nanocrystals. Such hybrid light emitting devices are promising for fabrication of low-cost, low-energy, and highly efficient light sources that can be used for general lightning in; full-color displays, imaging systems, miniature chemical and biological sensors. ${ }^{28-31}$

Recently a new class of hybrids designed to utilize Förster resonant energy transfer from excitations generated in the quantum well to excitons in the fluorescent layer has been suggested ${ }^{32-35}$. Two requirements should be satisfied in such hybrids; (i) a significant spectral overlap between the quantum well emission and the fluorescent layer absorption and (ii) the two materials (i.e. quantum well and fluorescent layer) have to be placed very close since the interaction distance between excitons is on the order of a few $\mathrm{nm}$. Structures like this, where the design satisfies these two requirements could be an ideal system for fabrication of a novel class of hybrids which can be considerably more efficient in terms of energy transfer than their radiative energy transfer analogues. This class of hybrid structures is discussed in Paper I, II and V and more details on the phenomenon of energy transfer in such structures can be found in Chapter 3 . 


\section{$1.2 \quad$ Research objectives}

This thesis is based on work performed in two adjacent projects during my time at Linköping University. In one part, the development of a group IIInitride growth process using reactive DC-magnetron sputtering. As mentioned above this material system is promising for cheap and efficient electronic devices. In another part, the aim was to fabricate and study hybrid structures based on GaN. The fundamental knowledge of such systems is still scarce. Limitations and possibilities needs to be studied and mapped. The outcome of this research is appended in 6 papers preceded by 6 chapters giving the reader an introduction to the field. 


\section{CHAPTER 2}

\section{Group III-Nitrides}

Group III-nitrides can crystallize in either wurtzite, zinkblende or rock salt structure. The wurtzite structure is thermodynamically favorable at both deposition and room temperatures (for all binary, ternary and quaternary alloys). This crystal structure is therefore the easiest to produce ${ }^{36,37}$. In the wurtzite structure the atoms are placed in the lattice points of two interpenetrating hexagonal close packed lattices. The lattices will be relatively shifted by $\frac{3}{8}$ the height of the lattice cell ${ }^{38}$ as illustrated in figure 2.1. Table 2.1 below summarizes the conventional way of naming planes and crystallographic directions in terms of Miller indices.

Table 2.1: Crystallographic conventions for naming planes and directions in a lattice.

\begin{tabular}{c|l}
\hline Nomenclature & Meaning \\
\hline$[\mathrm{hkl}]$ & One specific direction \\
$(\mathrm{hkl})$ & One specific plane \\
$\{\mathrm{hkl}\}$ & Crystallographically equivalent planes \\
$<\mathrm{hkl}>$ & Crystallographically equivalent directions
\end{tabular}

The bonds are polar covalent and each atomic species are placed in tetrahedral coordination due to the $\mathrm{sp}^{3}$ hybridization. A wurtzite structure does not have inversion symmetry, i.e. the direction [0001] and [0001] is not equivalent. [0001] is usually called positive c-direction while [000시 is usually called negative c-direction. 

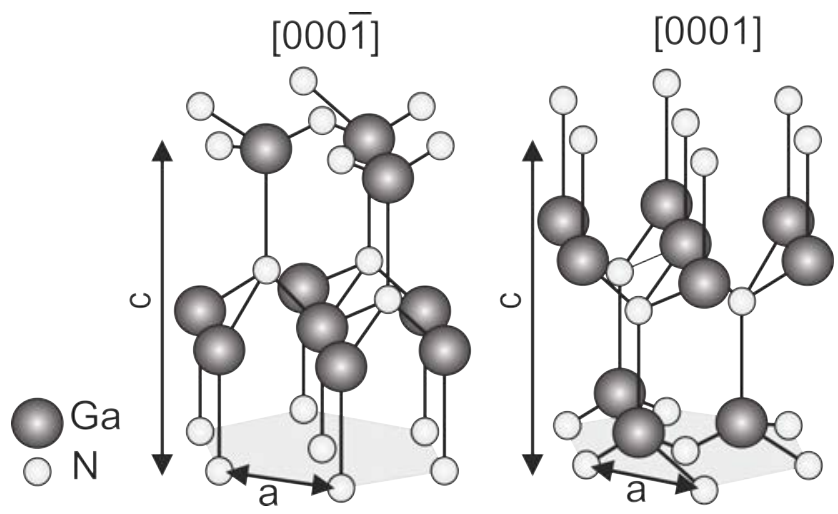

Figure 2.1: Illustration of the wurtzite structure. Notice the lack of inversion symmetry as the structure is flipped along the c-axis

If a GaN crystal is rotated $180^{\circ}$ while in [0001] direction, Ga and N will exchange positions with each other. Due to high ionicity of the Ga-N bond, a non-ideal tetragonal bonding configuration is formed. Thus the wurtzite structure exhibits a macroscopic polarization along the c-axis even in the absence of strain. This is called spontaneous polarization. The presence of lattice mismatch in heterostructures results in an additional contribution to the total polarization due to the piezoelectric effect. This is detrimental to LED technologies ${ }^{39}$ where a very thin film is sandwiched between materials with higher band gap forming a so called quantum well structure (QW). In III-nitride heterostructures grown in c-direction, the conduction and valence bands in the quantum well and in the barrier layers will be bent by this polarization, thus separating the charge carriers and consequently decreasing the probability of radiative recombination.

The lack of commercial GaN bulk substrates forces GaN layers or thin films to be grown heteroepitaxially. One way to circumvent this is to grow nanorods or similar geometries, which allows for strain related defects to diffuse towards the structure edges. The interest in group III-nitrides is caused by their spectacular optical and electrical properties making them suitable for different optoelectronic and electronic applications. All group III-nitrides are direct band gap semiconductors. A semiconductor with a direct band gap has the maximum of the valence band and the minimum of the conduction band at the same point in reciprocal space as will be discussed in Chapter 3. Table 2.2 summarizes lattice parameters and band gap energies of wurtzite AlN, GaN and InN. 
Table 2.2: Collected lattice parameters and band gap energies for wurtzite structured group III-nitrides. For more parameters see reference (40).

\begin{tabular}{l|l|l|l}
\hline Parameter & AlN & GaN & InN \\
\hline Lattice constant $(\mathrm{a})[\AA]$ & 3.112 & 3.189 & 3.545 \\
Lattice constant $(\mathrm{c})[\AA]$ & 4.982 & 5.185 & 5.703 \\
Band gap at RT $[\mathrm{eV}]$ & 6.25 & 3.510 & 0.78
\end{tabular}

In reality, no crystal is perfect. Besides vacancies and interstitials, defects such as stacking faults (SF) can be formed during growth. There are several different types of basal plane SFs typical for wurtzite GaN. Figure 2.2 illustrates typical stacking faults with Ga-N planes along the [0001] direction color coded for a visual aid. The three types of SFs are called intrinsic type I and II and extrinsic SF. The intrinsic type I SF has the lowest energy of formation per unit cell ${ }^{41}$. and is formed by a single violation of the stacking sequence through removing a single Ga-N layer (e.g. $\mathrm{A} \alpha$ ) followed by a slip of the crystal by $\frac{1}{3}\langle 10 \overline{1} 0\rangle$. Intrinsic type II SFs are formed by two violations of the stacking sequence through a direct shearing in a perfect crystal by $\frac{1}{3}\langle 10 \overline{1} 0\rangle$. Finally extrinsic SFs will form by insertion of an extra Ga-N layer (i.e. $\mathrm{A} \alpha \mathrm{B} \beta \mathrm{A} \alpha \mathrm{B} \beta \rightarrow \mathrm{A} \alpha \mathrm{B} \beta \mathrm{C} \gamma \mathrm{A} \alpha \mathrm{B} \beta$ ).

SFs may give rise to traps in the band gap that may localize carriers; thus, they are optically active and luminescence associated with SFs has been previously reported ${ }^{42,43}$. A single intrinsic type 1 basal plane SF in wurtzite GaN can be understood as $\sim 3$ monolayer of zinkblende GaN breaking the crystal structure. Since the band gap of cubic GaN is less than for wurtzite, the potential profile in vicinity of SFs will form a QW in c-direction. Taking into account the data of Stampfl et al. ${ }^{41}$ the conduction and valence band offsets are $\Delta E_{\mathrm{c}}=0,27 \mathrm{eV}$ and $\Delta E_{\mathrm{v}}=0.07 \mathrm{eV}$ respectively, thus, the QW is of type II. The hole confinement in such QWs can be insufficient. As discussed in Paper III, regularly distributed stacking faults in NRs can form a periodic arrangement similar to a multiple quantum well structure, which allows for better charge carrier confinement. 


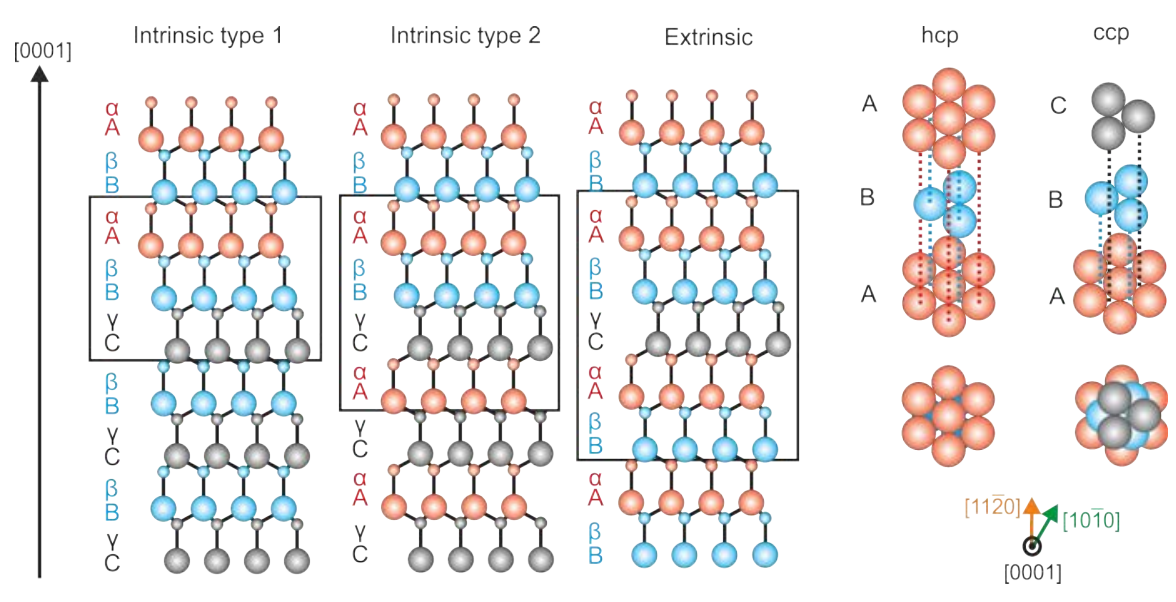

Figure 2.2: Simple illustration of intrinsic type 1 and 2 and extrinsic stacking fault in a wurtzite structure. Ga-N planes are color coded to aid the reader. SF regions are highlighted with boxes. Also added is the difference between a regular hcp and ccp stacking sequence

\subsection{Ternary group III-nitrides}

The ternary III-nitrides, $A_{x} B_{1-x} N$, can be carefully engineered in respect to composition. The behavior of the lattice parameter, $a$, and energy band gaps, $E_{\mathrm{g}}$ with the change of the composition can be described by Vegard's law (equation 2.1 and 2.2 respectively).

$$
\begin{gathered}
a\left(A_{\mathrm{x}} B_{1-\mathrm{x}} N\right)=x a_{\mathrm{A}}+(1-x) a_{\mathrm{B}} \\
E_{\mathrm{g}, \mathrm{A}_{\mathrm{x}} \mathrm{B}_{1-\mathrm{x}} \mathrm{N}}=x E_{\mathrm{g}, \mathrm{A}}+(1-x) E_{\mathrm{g}, \mathrm{B}}+b x(1-x)
\end{gathered}
$$

Where $b$ is the bowing parameter and $x$ is the molar fraction of $A$. Figure 2.3 shows the band gap energy as a function of lattice constant $a$ using the bowing parameter determined by the work of Vurgaftman et $a l .{ }^{40}$. A comprehensive collection of parameters of III- $\mathrm{V}$ alloys have been published by the same group ${ }^{44}$. With energy band gaps between $0.78 \mathrm{eV}$ and $6.25 \mathrm{eV}$ and lattice parameters, $a$, from $3.112 \AA$ to $3.545 \AA$ the Al-GaIn-N alloys offer a broad spectrum of engineering possibilities. From figure 2.3 some interesting results can be deduced. For example, InAlN can be made lattice matched to GaN while having a wider band gap. In theory this allows for strain free QW structures. InAlN also have a large refractive index contrast in respect to $\mathrm{GaN}$ which make such heterostructure promising as 
distributed bragg reflectors, or microcavities ${ }^{45}$. One problem with InAlN is, however, that the preferred stoichiometry is within a miscibility gap ${ }^{46,47}$. This means that when growing InAlN at thermodynamical equilibrium the alloy will easily phase separate into high In- and Al-containing regions ${ }^{48}$. To grow metastable phases below this critical temperature, reactive magnetron sputtering has been employed in this thesis work and this will be discussed in Chapter 4.

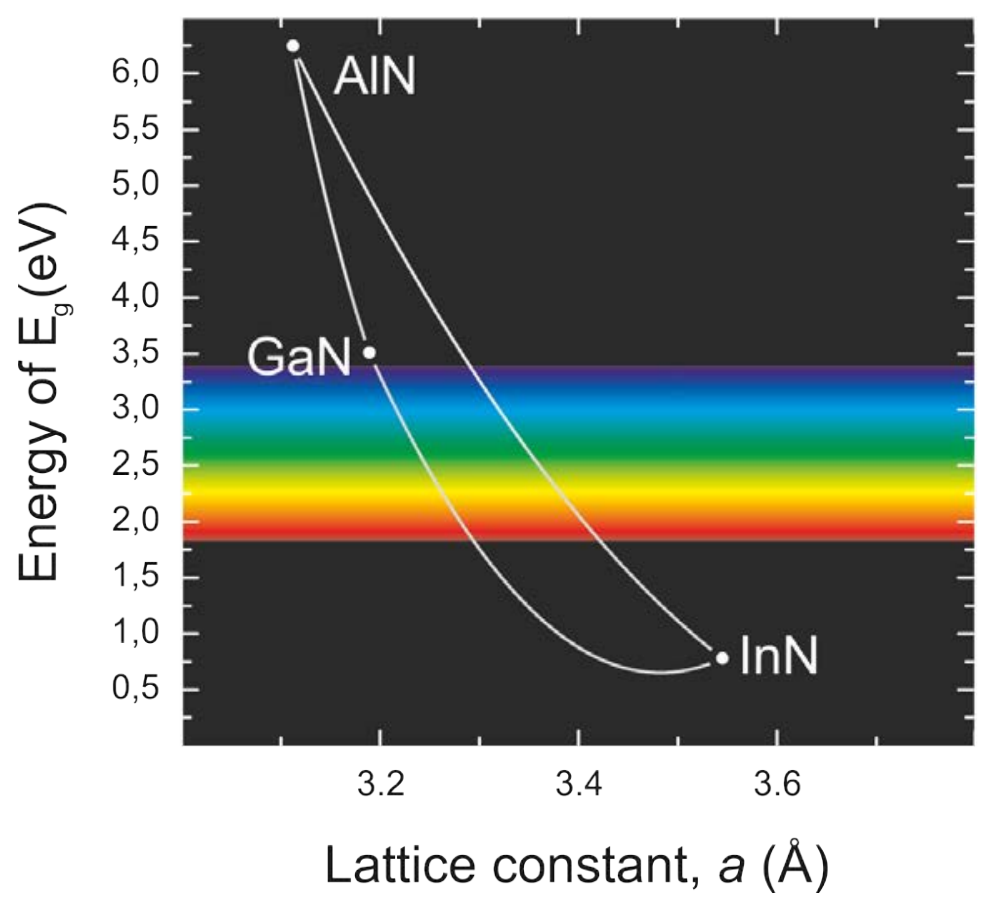

Figure 2.3: Band gap energy in $\Gamma$ point vs lattice constant $a$ plotted using the data obtained from I. Vurgaftman and J. R. Meyer ${ }^{40}$ 


\section{CHAPTER 3}

\section{Optical Properties of Semiconductors}

When an electron is moving across the crystal structure it experiences a periodic potential due to the nuclei in the crystal lattice. To find the energy of the particle we solve the Schrödinger equation for the periodic potential.

$$
\left(-\frac{\hbar^{2}}{2 m} \nabla^{2}+U(\mathbf{r})\right) \Psi(\mathbf{r})=E \Psi(\mathbf{r})
$$

Where $\hbar$ is the reduced Planck's constant, $m$ is the electron mass, $U(\mathbf{r})$ is the potential, $\Psi$ is the wave function describing the electron and $E$ is the energy of the electron. A schematic band structure diagram is illustrated in figure 3.1 where the top and bottom parabolas are allowed states. In semiconductors and insulators there is a gap between the two bands (Also illustrated in the figure). This gap is called the band gap $\left(E_{\mathrm{g}}\right)$ and is the region of energy for which there are no allowed states to occupy. The band below the band gap is called the valence band (VB) and the band above the band gap is called the conduction band (CB). By providing energy and momentum (excite) to an electron in the VB, it can change state by moving to the $\mathrm{CB}$ where it becomes mobile. The missing electron in the VB will give rise to a surplus of positive charge, a hole, which may move in the VB. Oppositely, if an electron change state from the CB to the VB, i.e. recombines with a hole, energy and momentum will be emitted. The energy and the momentum is provided/emitted in the form of a photon or a phonon (quantized lattice vibration), respectively. 
a)

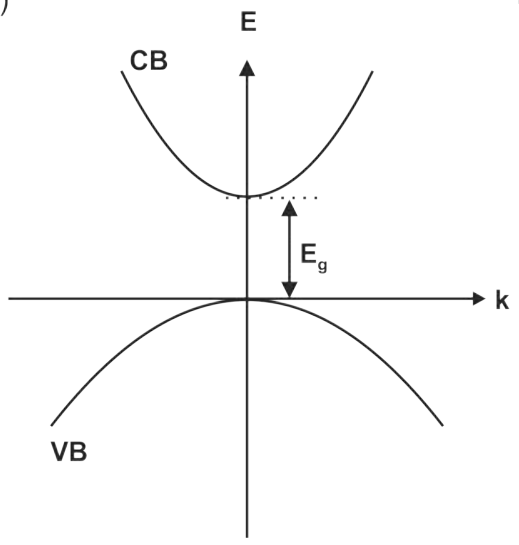

b)

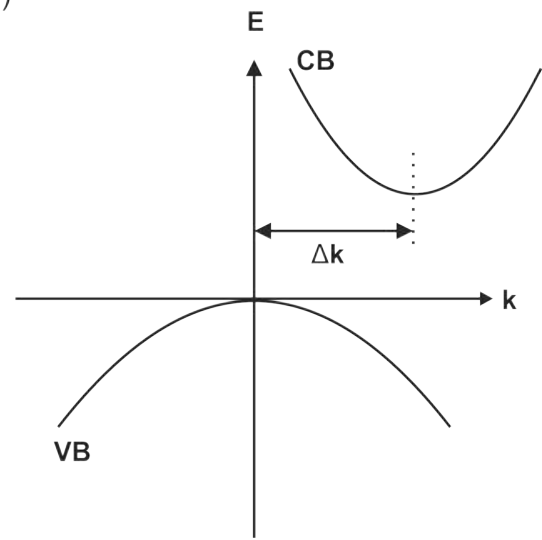

Figure 3.1: Schematic drawing of a band structure in semiconductors: a) Illustrates a direct band gap while b) illustrates an indirect band gap.

If the top of the VB and the bottom of the CB is at the same point in the reciprocal lattice (as in figure 3.1a) the band gap is called a direct band gap semiconductor. If, as shown in figure $3.1 \mathrm{~b}$, they do not align, it is called an indirect band gap semiconductor. Electron transitions between each band must adhere to the conservation of energy and momentum. Since photons carries almost zero momentum, photon emission is less probable to occur in an indirect band gap semiconductor. In that case, the electron must pass through an intermediate state and transfer/gain momentum by a phonon with a momentum that equals the difference in, $\Delta \mathrm{k}$, between the hole and the electron, i.e. phonon-assisted recombination. This three particle process is less probable and that is the reason why it is advantageous to use direct band gap materials for fabrication of efficient LEDs. SiC has similar band gap energy and break-down voltage and superior thermal conduction and thermal expansion compared to GaN. However, since it is an indirect band gap semiconductor it is not possible to produce a blue LED of sufficient efficiency $^{49}$. It is worth mentioning that $\mathrm{GaN}$ have hole states splitted into three subbands around VB maximum (which is at $\mathbf{k}=0$ ). This energy splitting occur due to crystal field splitting and spin-orbit coupling. Strain will also influence the band structure and the band gap in GaN will increase and decrease with compressive and tensile strain, respectively ${ }^{50}$.

The dispersion relation shows how the energy depends on the $\mathbf{k}$ vector. To know how many states are available with a given energy one use a concept of density of states, DOS, or $\mathrm{D}(\mathrm{E})$. The energy states available for electrons and holes are restricted by dimensionality as illustrated in fig- 
ure 3.2. In the top of figure 3.2 there are schematic drawings showing the energy dependence of DOS in the conduction band for different degrees of confinement. As the dimensionality decreases the DOS is becoming more restricted in energy.
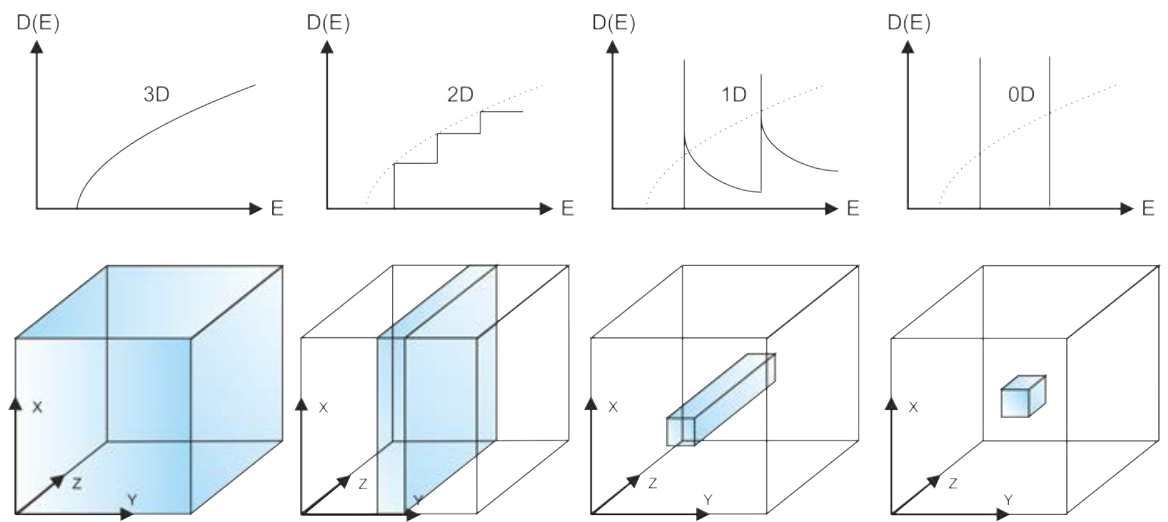

Figure 3.2: Schematic illustration of how dimensionality of the crystal affects the density of state. From left; 3D, 2D, 1D, 0D cases corresponding to bulk, quantum well, quantum rod and quantum dot respectively. The schematic drawings of DOS at the top illustrates the conduction band DOS for each case.

In metals the valence band and conduction band overlaps. The valence electrons are free to move across the lattice, this is what allows electric current to flow through the metal. In insulators and semiconductors the valence electrons are "static" forming bonds with the surrounding atoms. The band gap in diagrams shown in figure 3.1 is representing the required energy, which is needed for a valence electron to break from the bonds and to become a conducting electron, which can move freely across the lattice in similar ways as in metals. As stated above, when electrons are excited to higher energy states they leave a hole in the valence band. If the electron doesn't get enough energy to escape the hole it can be pulled back in by the Coulomb force and recombine to emit light or become an exciton. 
Excitons are electron-hole pairs bound by an attractive Coulomb force, and thereby form an electrically neutral quasi-particle.

$$
F=\frac{Q_{1} Q_{2}}{4 \pi \epsilon_{0} \epsilon_{r} r^{2}}
$$

Where $Q_{1}$ and $Q_{2}$ are the carrier charges separated by a distance $r, \epsilon_{0}$ is the vacuum permittivity and $\epsilon_{r}$ is the dielectric constant of the material. Excitons are usually separated into two types based on their Bohr radius; the Frenkel exciton (exciton with small Bohr radius) and the Wannier-Mott exciton (having a large Bohr radius). The attractive force between the two charges decreases if $\epsilon_{r}$ increases. The Frenkel excitons are therefore found in polyfluorenes (where $\epsilon_{r}$ is below $\left.\sim 4\right)^{51}$ while in the group III-nitrides (where $\epsilon_{r}$ is $\left.5-20\right)^{52}$ the Wannier-Mott excitons will be formed. Exciton binding energies are on the order of $0.1-1 \mathrm{eV}$ and $0.01-0.1 \mathrm{eV}$ for Frenkel and Wannier-Mott respectively and the Bohr radius are on the order of a few $\mathrm{nm}$ to 10 's of $\mathrm{nm}$ for Frenkel to Wannier-Mott, respectively. This will introduce interesting differences between the materials. For example, the Wannier-Mott excitons start to interact at much lower densities in the material because their wave functions are more spread. This allows for optical nonlinearity due to many-particle effects ${ }^{53}$.

The luminescence emitted from the sample following a radiative recombination has different names, e.g.; cathodoluminescence, electroluminescence and photoluminescence depending on the source that provided the energy for the excitation of the electron, which is electron bombardment, electric field and electromagnetic radiation, respectively. Figure 3.3 illustrates several possible recombination processes. All transitions shown are radiative except (a) and (b) which is the excitation from VB to $\mathrm{CB}$ and relaxation of the excited electron (or hole) to the CB (VB) minimum (maximum), respectively. Upon free carrier recombination the emitted photons have higher energies than upon exciton recombination (as shown in figure $3.3 \mathrm{c}, \mathrm{d}$ ) because of the binding energy of the exciton. In bulk GaN the binding energy of an exciton is about $20 \mathrm{meV}$ while it is slightly increased to $28-35 \mathrm{meV}$ in quantum well structures according to theoretical predictions ${ }^{54}$. The difference can be understood in terms of the exciton energy being determined not only by the Coulomb potential, but also by the carrier confinement in a potential well (i.e. the space the carriers are allowed is limited by the thickness of the quantum well). If the space allowed for the carriers are on the order of the exciton Bohr radius then the exciton is considered to be quantum confined. 


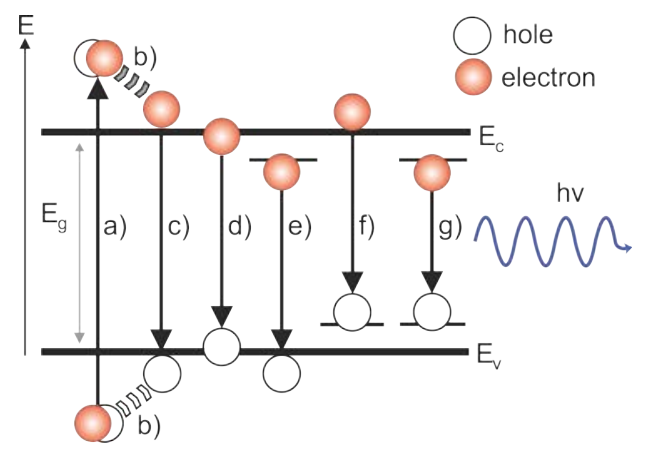

Figure 3.3: Schematic drawing of optical transitions in a semiconductor. Different processes are shown; a) the excitation of an electron from within the valence band to the conduction band; b) the non-radiative relaxation of the electron and hole down to the respective band edge; c) the free carrier radiative recombination; $d$ ) the free exciton radiative recombination; e) the donor bound exciton recombination; f) the acceptor bound recombination; g) the donor-acceptor pair recombination.

In thermodynamic equilibrium the rate of creation and rate of recombination of electron-hole pairs are equal. The system can be placed outside of equilibrium by a created deviation in electron and hole densities which change the total electron and hole densities (such as in our photoluminescence measurements). If we leave the system to evolve freely the concentrations will return to equilibrium values with time. The lifetime of the minority carriers, i.e. how long the minority carrier exist in its current excited state, governs the dynamics of recombination within the material. The lifetime will vary depending on origin of the transition. In the group III nitride structures studied in this work the total recombination rate could be described as the sum of the non-radiative and radiative recombination components

$$
k_{\text {tot }}=k_{\text {radiative }}+k_{\text {non-radiative }}
$$

Using time-resolved photoluminescence (TRPL) methods we can resolve how the intensity of the radiative transition decay with time. The data obtained is generally expressed by the following equation

$$
I(t)=I_{0} e^{\frac{-t}{\tau}}
$$

Where $I_{0}$ is the background intensity and $\tau$ is the lifetime such that

$$
k_{t o t}=\tau^{-1}
$$




\subsection{Förster resonance energy transfer}

Different hybrid structures have been fabricated and studied in Paper I, II and $\mathbf{V}$ with the aim to investigate possible resonant energy transfer mechanisms which could be Förster resonance energy transfer (FRET). Hybrid structures utilizing FRET was briefly discussed in the introduction, the basics of the phenomenon of FRET will be covered here.

The theory was first published by the German physical chemist Theodor Förster ${ }^{55-57}$ and was originally developed to study the equilibrium and dynamical properties of organic compounds or biopolymers. This means the theory of FRET was developed for Frenkel $\Leftrightarrow$ Frenkel exciton interactions. In recent years however, both Frenkel $\Leftrightarrow$ Wannier-Mott and WannierMott $\Leftrightarrow$ Wannier-Mott interactions has been studied ${ }^{34,53,58,59}$.

To discuss FRET in the context of this thesis let us assume a hybrid structure based on an inorganic QW structure in combination with a polyfluorene (see figure 3.4a). If we choose a QW structure and a polyfluorene with spectral overlap between the QW emission and the polyfluorene layer absorption placed close to each other we can create a dipole-dipole interaction between excitons in these two materials ${ }^{35}$. FRET is a nonradiative energy transfer mechanism, i.e. no photon is involved in the energy transfer. Figure $3.4 \mathrm{~b}$ show a generic energy level diagram describing the FRET process.

a)

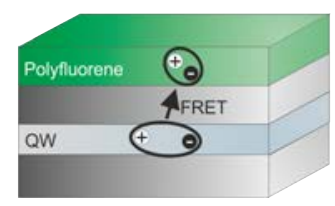

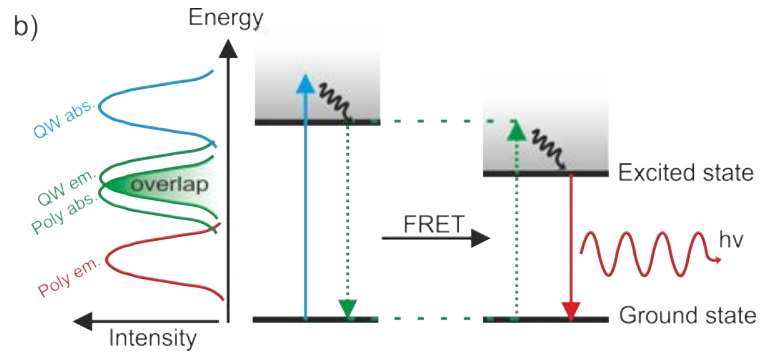

Figure 3.4: (a) Schematic drawing of a hypothetical hybrid structure and (b) Illustration of energy transfer based on the FRET mechanism in an energy diagram. The required spectral overlap is also included. 
The rate of FRET is dependent on the distance between the dipoles, $\mathrm{R}$, following an inverse power $\operatorname{law}^{58}$ :

$$
k_{F R E T}=\frac{1}{\tau}\left(\frac{R_{0}}{R}\right)^{C}
$$

Where $\tau$ is the fluorescence lifetime (in our case) of the inorganic QW component and $R_{0}$ is the system specific Förster radius. When the interexciton distance $R$ is equal to or smaller than $R_{0}$ the transfer rate is equal to or higher than the fluorescence lifetime. $R_{0}$ depends on many factors such as dipole angular orientation, spectral overlap integral and donor quantum yield. One should also note that the exponent $C$ depends on the nature of the dipole-dipole interaction such as degree of exciton confinement. Equation 3.6 was developed for interactions between two Frenkel excitons and therefor values of $C=6$ is often found in the literature. The exponent $C$ has however been shown to vary between 2 and 6 for exciton interactions in QW-QW and QD-QD, respectively. ${ }^{60-62}$

Further on, it has been shown that this process is very fast, on the order of $10-100$ ps depending on system ${ }^{35,63}$. That rate should be compared to the lifetime of excitons which is generally rather long in quantum wells. That means that the FRET from the quantum well exciton to the exciton in the polyfluorene can occur faster than other radiative and non-radiative recombination processes.

By using TRPL, we can obtain information about the QW recombination rate. The QW recombination rate in absence of a polyfluorene overlayer, $k_{Q W}$, will be the same as $k_{t o t}$ described in equation 3.3. The recombination rate of the $\mathrm{QW}$ in prescence of a polyfluorene overlayer (i.e. as a hybrid structure) can be written as:

$$
k_{Q W}^{H}=k_{\text {radiative }}+k_{\text {non-radiative }}+k_{\text {additional }}
$$

If we assume the additional contribution $k_{\text {additional }}=k_{F R E T}$ i.e. that the additional decay rate is due to, and only due to, FRET we could start to indirectly investigate the phenomenon. However, this assumption should be performed with great caution. 


\section{CHAPTER 4}

\section{Thin Film Deposition}

To expand the range of applications and further develop applications of III-nitrides, processes for low-temperature growth of single crystalline material needs to be developed. By using lower temperatures, the biaxial stress induced by heteroepitaxial growth on substrates with different thermal expansion coefficient from the film can be reduced and the compositionally unstable nature at high growth temperatures of In-rich III-nitride materials can be avoided. Moreover, by using lower growth temperatures, integration of GaN based devices with other semiconductor technologies such as the Si CMOS technology may be possible ${ }^{64}$. Metal-organic chemical vapor deposition (MOCVD) is commonly used for growth of GaN today, however, the temperature has to be sufficiently high to overcome the activation energy barriers to precursor chemisorption and surface adatom migration. Thus, for low-temperature growth, other techniques are required. Magnetron sputtering is a potentially applicable technique in that it is possible to deposit films at low temperature and a wide range of materials can be grown. It is also relatively easily to scale-up the process to for deposition of large area films. Thus, the growth technique the thesis has been focused on is magnetron sputtering and the samples in Paper III, IV, V and VI were all grown using magnetron sputtering. The chapter will also briefly discuss the basics of vacuum science since its fundamental to sputtering and MOCVD. MOCVD has been used for the samples studied in Paper I and II. 


\subsection{Vacuum science}

The demand for good quality materials keeps increasing as new technologies emerge. By fabricating thin films in a high vacuum, better control of the contamination level can be achieved. Additionally, in vacuum, the mean free path of particles increases, which allows atoms to reach the substrate easily. There are 5 vacuum regimes based on pressure regions, as summarized in table 4.1. This work uses a reactive direct current magnetron sputter system with a base pressure in the range of $\sim 10^{-6} \mathrm{~Pa}$.

Table 4.1: Definitions of different vacuum regimes and their pressure ranges in Pascal

\begin{tabular}{l|l}
\hline Type of vacuum & \multicolumn{2}{|l}{ Pressure range $(\mathrm{Pa})$} \\
\hline Low vacuum & $10^{5}>\mathrm{p}>3.3 \cdot 10^{3}$ \\
Medium vacuum & $3.3 \cdot 10^{3}>\mathrm{p}>10^{-1}$ \\
High vacuum & $10^{-1} \quad>\mathrm{p}>10^{-4}$ \\
Very high vacuum & $10^{-4} \quad>\mathrm{p}>10^{-7}$ \\
Ultra high vacuum & $10^{-7}>\mathrm{p}>0$
\end{tabular}

A central physical quantity in vacuum theory is the mean free path, $\lambda$. The mean free path is the average distance a particle travels between collisions. The expression for mean free path is ${ }^{65}$ :

$$
\lambda=\frac{k_{B} T}{\sqrt{2} \pi d^{2} p}
$$

Were $k_{B}$ is the Boltzmann's constant, $T$ is the temperature, $d$ is the diameter of the gas particle and $p$ is the pressure. A high vacuum means that the mean free path is long, i.e. the particle can travel rather far without colliding. In figure 4.1 the mean free path for $\mathrm{N}_{2}$ and $\mathrm{H}_{2}$ vs the pressure has been plotted using equation 4.1 with bond-length values from Ref.(66) assuming room temperature (293 K). The mean free paths for the typical deposition pressures (in yellow) and base pressures (in blue) in my sputtering experiments are highlighted to aid the reader. The reactive gas used during this work has been nitrogen gas and this is why this is used as an example. For reference, hydrogen gas is also displayed. At the base pressure the mean free path is on the order of $10^{5} \mathrm{~m}$ while at the deposition pressure the mean free path is around a few decimeters. 


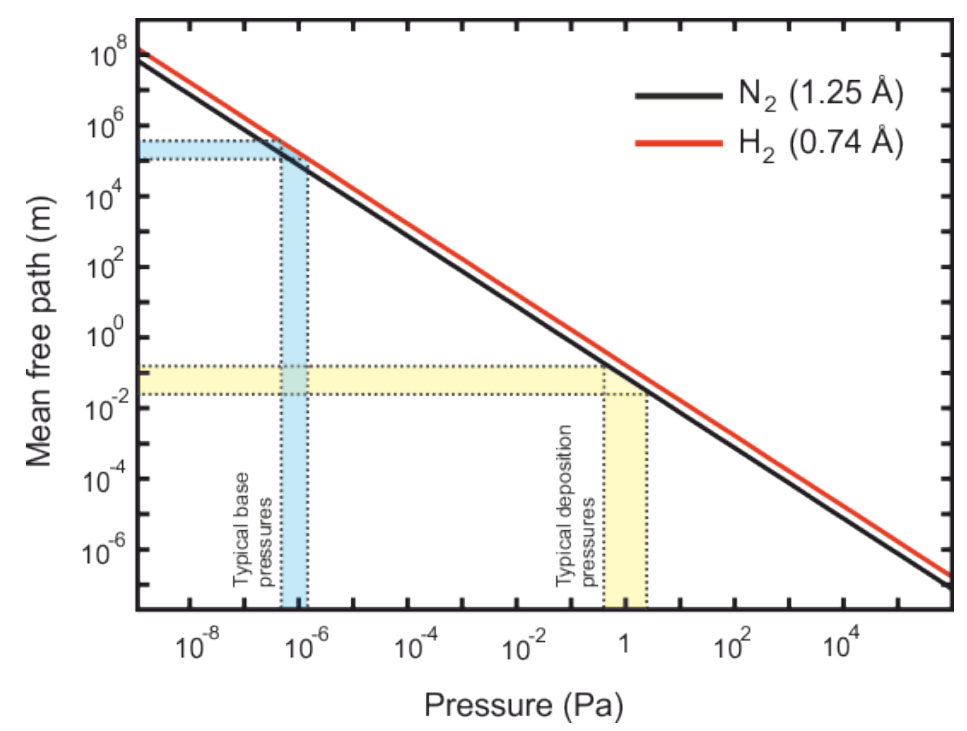

Figure 4.1: The mean free path vs pressure for nitrogen and hydrogen gas as a double logarithmic plot. The figure is plotted using equation 4.1 with bond-length values from Ref.(66) and a temperature of $293 \mathrm{~K}$. Mean free paths obtained for pressure ranges of the depositions and base pressures are included in yellow and blue respectively.

Other central physical quantities are the dimensionless Knudsen, $K n$, and Reynolds, Re, numbers. Using Reynolds number is a way to predict how the fluid flow patterns will behave in different flow situations while Knudsen number gives guidelines if statistical or continuum mechanics can be used in predictions of the flow. The Knudsen and Reynolds numbers can be expressed as:

$$
\begin{gathered}
K n=\frac{\lambda}{L} \\
R e=\frac{U \rho L}{\eta}
\end{gathered}
$$

Where $L$ is a typical dimension length of the system, such as the length between the chamber walls, $U$ is the flowing stream velocity in the pipe, $\rho$ is the mass density and $\eta$ is the viscosity of the gas. Different regions of flow can be distinguished and predicted by these dimensionless numbers. Figure 4.2 provides an overview of these regions. At the lowest pressure there are no particle-to-particle interactions within the dimensions of the 
vacuum system. This region is called the molecular flow regime and is characterized by a Knudsen number bigger than 1, i.e. the length scale of the system is larger than the mean free path of the particles. Reynolds number has no physical meaning in this region. The molecular flow regime is the best known regime ${ }^{67}$. For Knudsen numbers between 1 and 0.01 there is a transitional flow regime where the flow can be either viscous or molecular.

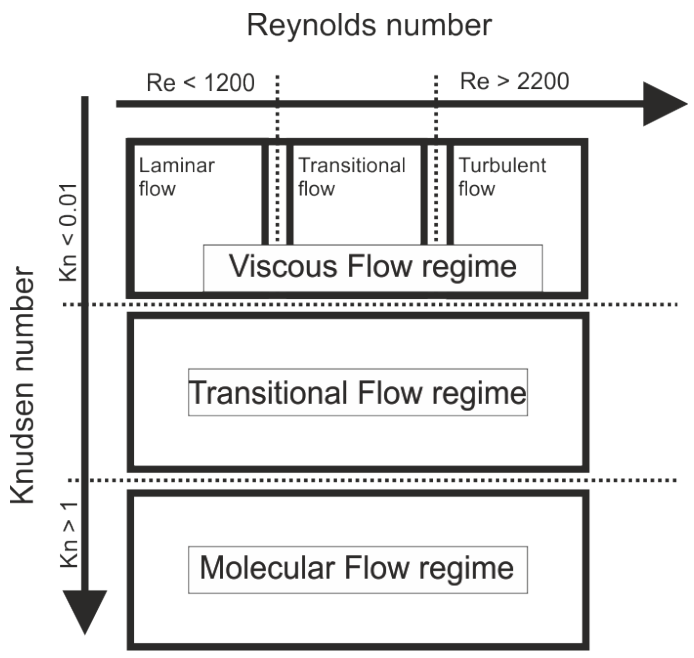

Figure 4.2: Schematic overview of Knudsen number vs Reynolds number for gas flow regimes.

For Knudsen numbers less than 0.01 the gas is found in a viscous flow. The viscous behavior can be categorized into two types of flow. At Reynold numbers less than 1200, the gas is flowing in parallel layers with no lateral mixing, and this is called a laminar flow. At Reynold numbers higher than 2200 the gas is flowing in a shifting manner and undergoes rapid variations in local pressure and velocity. This regime is known as turbulent flow. The turbulent flow is more difficult to describe. At Reynolds numbers between 1200 and 2200 there is a transitional regime where the gas flow can be either laminar or turbulent. 


\subsection{Sputter deposition}

Sputtering is a process in which atoms are ejected by ion bombardment ${ }^{68,69}$. If the ejected atoms are deposited on a substrate, we refer to the process as sputter deposition. Sputter deposition is a physical vapor deposition (PVD) technique in contrary to e.g. chemical vapor deposition (CVD) techniques. Sputtering was first reported by Sir William Robert Grove ${ }^{70}$ while studying the electrical conductance of gases in the mid- $19^{\text {th }}$ century. Grove and his contemporaries, however, attributed this to thermal processes. Today, as mentioned, there is an understanding that sputtered atoms are ejected by impinging ions. The source of these ions can be plasma. The term "plasma" was first coined by Tonks and Langmuir ${ }^{71}$ in 1929. Plasma is a quasi-neutral collection of electrons, neutral particles and ions exhibiting a collective behavior. Many of them glow in beautiful colors due to the deexcitation of metastable energy states of the species involved in the process. Plasmas are created by ionizing gas, e.g. by having gas entering a chamber and applying a negative potential to the target. In direct current sputter deposition, the target essentially acts as a cathode and the chamber walls act as the anode. Positive ions are accelerated towards the negative target by Coulomb's force, at the same time electrons are repelled. Ions that hit the target surface could set off a collision cascade. The transferred energy from ion to target is proportional to the mass of the target atom and the incident ion $^{65}$ :

$$
E_{\text {transfer }} \propto \frac{4 M_{\text {target }} M_{\text {ion }}}{\left(M_{\text {target }}+M_{\text {ion }}\right)^{2}} \cos \theta^{2}
$$

Where $M_{\text {target }}$ and $M_{\text {ion }}$ are the atom masses of the target and ion, respectively. Similar atom masses are preferable in the sputtering process. $\theta$ is the angle between the direction of the incident ion before the collision and the direction of the target atom after the collision as illustrated in figure 4.3. If the transferred energy in the collision cascade is high enough to overcome the surface binding energy a target atom can be ejected (sputtered). The energy of the atoms and ions arriving to the sample surface is dependent on many things such as plasma density, sample bias and magnetron field to name a few.

Sputter deposition is a line of sight technique, which makes it hard to deposit into deep trenches. However, the sputter deposition can be done at much lower temperatures than CVD, which is highly appreciated in electronic industry where the substrates can be temperature sensitive. If sputtering is done in reactors kept in very high or ultra-high vacuum base pres- 
sures, which is the case in our laboratory, it is also a very clean method (in respect to impurity concentration). However, the high kinetic energy ions bombarding the surface in a sputter process will disturbed the already deposited crystal structure which may introduce crystalline defects in the film. This is avoided in CVD and is one of the main reason for its success for growing optoelectronic group III-nitrides

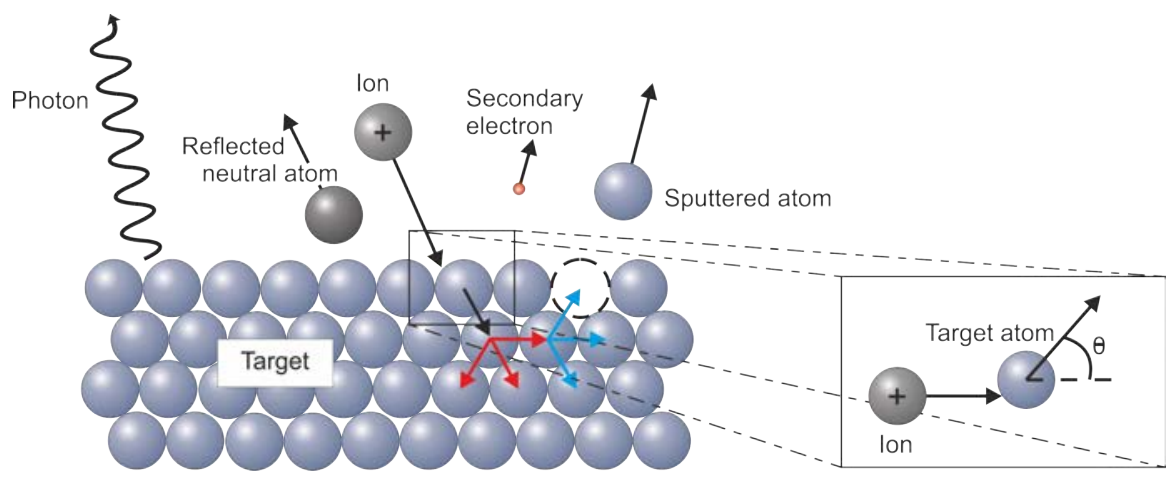

Figure 4.3: Schematic illustration of the sputter process. The most important processes are; the formation of sputtered atoms and collision cascades. The formation of photons, secondary electrons and reflected neutral atoms formed from ion interaction with surface are also included. The drawing to the right illustrates the definition of angle $\theta$ in equation 4.4 .

\subsubsection{Growth modes}

In an ideal world, the only existing crystal defect would be the surface, and the surface would be perfect. Ad-atoms would arrive to the substrate surface and randomly diffuse until they encounter another ad-atom and form a dimer. In reality, no surfaces are perfect. Surface defects and contaminations will always be present. These can trap the first ad-atoms in the initial stage of the growth. After the initial stage there are different morphological modes of thin film growth. They can be understood from a thermodynamical perspective. By comparing the surface energies of the substrate, $\gamma_{s}$, the deposited film, $\gamma_{f}$, and the interface between the film and the substrate, $\gamma_{i}$, one arrive at two relations:

$$
\begin{aligned}
& \gamma_{s}<\gamma_{f}+\gamma_{i} \\
& \gamma_{s} \geq \gamma_{i}+\gamma_{f}
\end{aligned}
$$


Nature seek to minimize energy. Relation 4.5 describe a preference for creating open substrate surface (substrate-vapor interfaces). This will result in the so called the Volmer-Weber growth mode $(\mathrm{V}-\mathrm{W})$, or island growth mode. Relation 4.6 describe a preference for eliminating substrate surface. This will result in the so called the Frank-Van der Merve growth mode (F$\mathrm{M}$ ), or layer-by-layer growth mode. A third growth mode has been defined as the complex combination of the change in surface energy and strain relief and is called the Stranski-Krastanov growth mode (S-K). S-K start with F$\mathrm{M}$ but change to $\mathrm{V}-\mathrm{W}$ after a critical thickness. This happens when the film covering the substrate surface and becomes the new substrate surface. If the film surface energy, acting as the new substrate surface, becomes energetically preferred to maintain, islands will be grown instead ${ }^{65}$. An illustration of the three different growth modes as time progress are displayed in figure 4.4 .

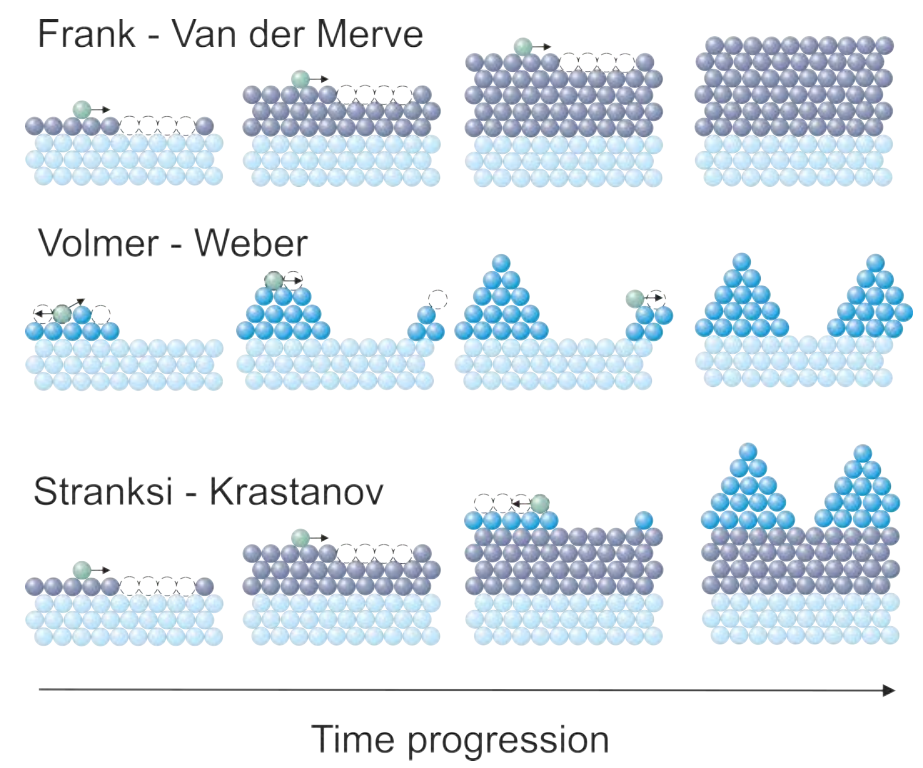

Figure 4.4: Schematic illustration of the three different types of growth modes as they progress with time

After nucleation and successful coalescence the growth will proceed to form thin films or nanostructures. Figure 4.5 show how the micro-structure evolves with increasing homologous temperature, $\mathrm{T}_{\mathrm{s}} / \mathrm{T}_{\mathrm{m}}$, according to a structure zone model ${ }^{72}$. $\mathrm{T}_{\mathrm{s}}$ is the substrate temperature and $\mathrm{T}_{\mathrm{m}}$ is the melting point of the film being grown. The model discussed here is the sim- 
plest case and only regard pure elemental films without impurities. Revised models has been published including varying inert/reactive gas partial pressures and ion bombardment ${ }^{73-75}$. In figure 4.5 three zones are recognized, all of which can be understood in terms of activation energy of diffusion processes. Zone I occur when substrate temperatures are low leading to slow surface diffusion of ad-atoms. This results in a fibrous or highly textured structure. As temperature increases mobility increases and the grains grow slightly larger. Increasing temperature further will allow for ad-atoms to have sufficient energy to cross the grain boundaries and we enter zone T. These temperatures are not high enough to give a clear preferred crystallographic orientation during the nucleation and grain coarsening stages. Because of different growth rates of different crystallographic planes this zone is usually observed to form films with high surface roughness. By increasing the substrate temperature even further we arrive at zone II. Here the temperature is high enough to allow for significant bulk diffusion. This means that grains can grow larger as grain boundaries can diffuse to minimize grain boundary and surface energies within the film.

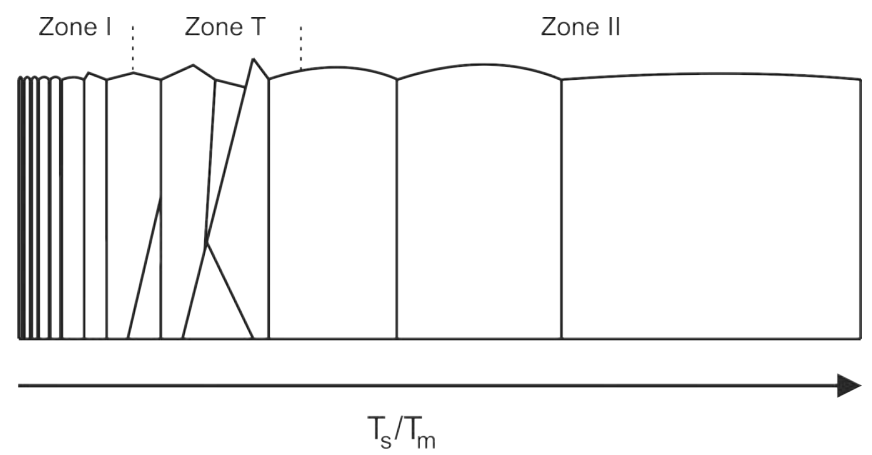

Figure 4.5: Schematic illustration of the micro-structural evolution in respect to homologous temperature, $\mathrm{T}_{\mathrm{s}} / \mathrm{T}_{\mathrm{m}}$, for a pure elemental film. Image redrawn after Petrov et al. ${ }^{72}$. $\mathrm{T}_{\mathrm{s}}$ is the substrate temperature and $\mathrm{T}_{\mathrm{m}}$ is the melting temperature of the material

\subsubsection{Reactive sputtering}

Sputter deposition can be used to deposit pure metal films with low concentration of impurities. However, it requires that the gas used in the sputter process do not form chemical bonds to the sputtered atoms at the substrate. The way to assure this is to use inert gas, such as noble gases. Argon is relatively cheap and is often used as a working gas. On the other hand, 
sputtering can have complicated reactive processes if there is a chemical reaction forming the film. In such case, the process is called reactive sputter deposition. If a reactive gas such as oxygen or nitrogen is used to react with sputtered material, compounds, namely oxides or nitrides can be formed by chemical reactions ${ }^{76,77}$. A rather common approach is to use a mixture of inert and reactive gases. In this work, nitride films were fabricated by the reaction of sputtered aluminium, gallium and indium atoms from the respective targets in either a pure nitrogen gas atmosphere or a mixture of nitrogen and argon. When sputtering in a pure reactive atmosphere, the target can get poisoned. Poisoning is when the ions of the plasma starts to react with the target surface. The target needs to be negatively charged to attract positive ions and if the target is poisoned so that an insulating film is formed, an observed phenomenon called arcing occurs. Arcing is disadvantageous in DC sputter deposition since it donates large amounts of energy to a small point of the target surface which can eject macro-particles that destroy the film. Even if the poisoning forms conductive films, it is still worth avoiding because the process will be different from sputtering using a new target. There will be a change in surface binding energy, introducing a change in sputtering rate and the difference in target stoichiometry could reflect the stoichiometry of the film. A hysteresis effect can be observed when monitoring the reactive gas partial pressure vs reactive gas flow. This is illustrated in figure 4.6. Three modes can be distinguished, namely; metallic mode, transition mode, poisoned mode. In the metallic mode increasing gas flow will not significantly increase the partial pressure. This is because any excess gas becomes consumed by the target, the film growth and the vacuum pump. In contrast, the poisoned mode is reached when excess gas can no longer be consumed. The increasing of gas flow will therefore lead to a linear increase in partial pressure. In the middle there is a transition mode region. Here, the gas pressure is very hard to control. The hysteresis shape of the curve is the manifestation of the different sputter rates of metallic vs poisoned targets. Moving forward (blue arrows) in figure 4.6 the transition occurs as the target surface becomes a nitride. Moving backward (red arrows) in figure 4.6 the transition occurs as the target surface becomes a metal. Most times it is desired to have a high growth rate in your process. Increased chamber pressure generally increase the growth rate since reaction rates increase with the number of interactions. However, film growth in high reactive gas pressures, as discussed, will lead to poisoning. The transition mode allows for high chamber pressure while the target is not poisoned. It is therefore very important to be able to control since it potentially could yield control of the stoichiometry at high deposition rates. 


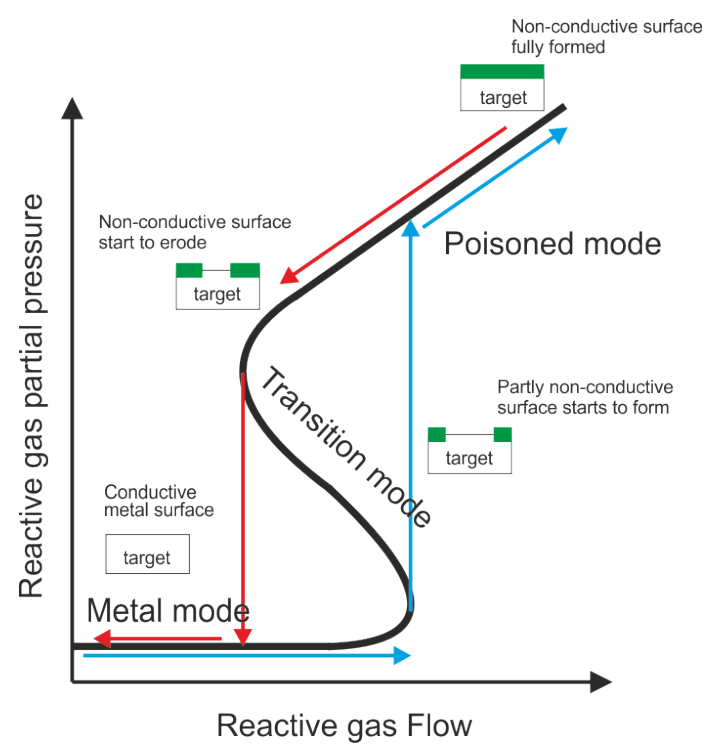

Figure 4.6: Schematic hysteresis curve. Blue arrows indicate increasing nitrogen flow. Red arrows indicate decreasing nitrogen flow.

\subsubsection{Magnetrons}

In a basic sputter process, secondary electrons can be ejected. In such cases they are repelled by the negative cathode and lost to the chamber walls. A magnetron can be used to spatially contain the electrons and maintain the plasma close to the target surface. Magnetrons are constructed to produce a magnetic field over the target in such a way that the field is, parallel to, and in the vicinity of, the target surface. Secondary electrons produced during the sputter process are trapped in this magnetic field due to Lorentz forces, $\mathbf{F}$ :

$$
\mathbf{F}=q(\mathbf{E}+\mathbf{v} \times \mathbf{B})
$$

Where $q$ is the particle charge (in this case the elementary charge), $\mathbf{E}$ is the electric field, $\mathbf{v}$ is the particle velocity, and $\mathbf{B}$ is the magnetic field. The trapped electrons continue to ionize neutral atoms close to the target, and thereby sustain the plasma. Ions are also affected by the magnetic field but not really confined due to their greater mass. Ions are instead confined by the electrons to maintain the plasma neutrality. The higher ionization rate obtained using a magnetron increases the sputter rate and in 
turn the deposition rate in general ${ }^{65}$. Because sputtered atoms are neutral, they are unaffected by the magnetic field. Fundamental plasma physics implies that the pressure must be sufficiently high for the particle density to sustain the plasma. The second advantage of using a magnetron is that the pressure can be decreased further while still maintaining the plasma thanks to the higher ionization rate. By lowering the pressure in the chamber, films can be produced with a higher purity and less material will be lost to the chamber walls during process. Figure 4.7 illustrates cross section view of a typical magnetron consisting of two strong concentric circular magnets placed behind the target in one of three configurations. In an unbalanced type I magnetron there is a stronger core magnet than the compensating outer surrounding magnet. In the balanced magnetron these two magnets are balanced in strength. In the unbalanced configuration of type II we have the opposite situation to type I. The surrounding magnet is stronger and cannot be balanced by the core magnet. The unbalanced type II magnet is preferable for our depositions since higher plasma densities can be achieved close to the substrate without increasing substrate bias. The increasing of substrate bias is accompanied by formation of defects and incorporation of stress in the film ${ }^{78,79}$. The higher plasma densities close to the substrate surface increase the ion bombardment which is used to modify the properties of the growing film. An unbalanced type I magnetron would be preferred if instead a high sputter yield is the concern. The plasma from a type I magnetron does not reach as far out which means fewer electrons are lost.

One disadvantage using a magnetron is that the target erosion will occur in the position where the magnetic field is perpendicular to the target surface. This will be seen as a dimple in the target over the middle magnet as well as a trench (also called "race-track") in the target over the surrounding magnet. This effect results in a reduction of target material that can be used during the lifetime of the target. 


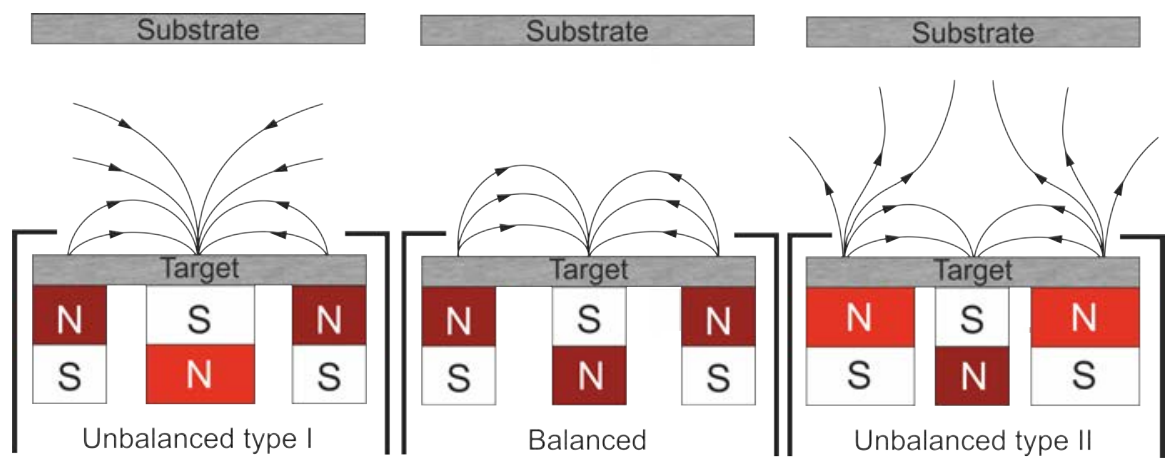

Figure 4.7: Schematic illustration of three types of magnetrons in cross sectional view. All are of North-South-North configuration and of either unbalanced type I, II or the balanced type. Unbalanced type II magnetron is the preferred configuration for our deposition systems.

\subsubsection{The reactors}

The chamber used for the growth of GaN is called Nidhögg (a dragon in Norse mythology). The base and working pressures are measured with an ion gauge and a capacitance manometer, respectively. The base pressure is in the range of $5 \cdot 10^{-9}$ Torr $\left(6.67 \cdot 10^{-7} \mathrm{~Pa}\right)$. A schematic illustration of the reactor is shown in figure $4.8 \mathrm{a}$. The chamber used to grow InAlN and AlN is called Ragnarök (the series of events foretold in Norse mythology to bring the end of the world). The base and working pressures are measured with a cold cathode gauge and capacitance manometer, respectively. The base pressure is in the range of $10^{-8}$ Torr $\left(1.3 \cdot 10^{-6} \mathrm{~Pa}\right)$. A schematic illustration of the reactor is shown in figure $4.8 \mathrm{~b}$. Both reactors are constructed in stainless steel with copper gaskets to seal all flanges except for the Ga magnetron in Nidhögg. The chambers are connected to a transfer tube and a load lock chamber (figure 4.8c), thus the sample is not exposed to the atmosphere when moved in between the chambers. The pumping speed can be regulated with a butterfly baffle valve in both reactors. The process gas flow rates are controlled with mass flow controllers calibrated for the specific gases. The purity of $\mathrm{Ar}$ and $\mathrm{N}_{2}$ gas can be reached to $99.999999 \%$ by using gas purifiers. In Nidhögg a $99.99999 \%$ pure Ga target is contained in a water-cooled horizontal $50 \mathrm{~mm}$ stainless steel trough mounted on a type II unbalanced magnetron. Ga has a melting temperature of $29{ }^{\circ} \mathrm{C}$ and will therefore be liquid during the deposition. The gallium target being a liquid provides two advantages: 
1. No target erosion

2. Continuous supply of fresh material to the surface.

Ga target is prepared from melting pellets directly into the steel trough. The target is solidified by placing the trough on a liquid nitrogen cooled holder. After being installed in the chamber, the target is thoroughly cleansputtered in pure Ar gas before usage. Ragnarök use $99.999 \%$ pure $(75$ $\mathrm{mm}) \mathrm{Al}$ and $(50 \mathrm{~mm})$ In targets placed with a $30^{\circ}$ angle in respect to the sample surface normal. For thin films this means rotation is important for a homogeneous distribution of In and $\mathrm{Al}$ across the film. However, it allows for other interesting possibilities such as growing chiral InAlN nanorods ${ }^{80}$. Targets are in contact with a water cooled copper plate and mounted on a type II unbalanced magnetron. 
a)

Nidhögg

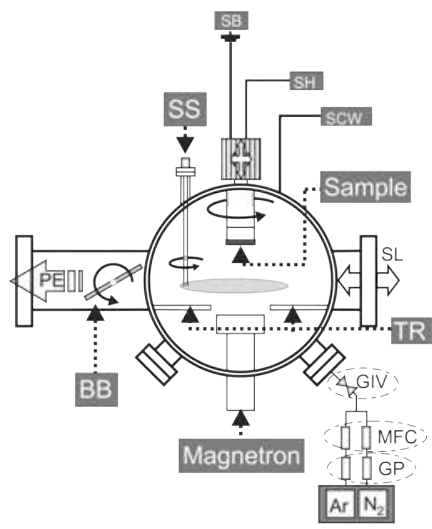

b) Ragnarök

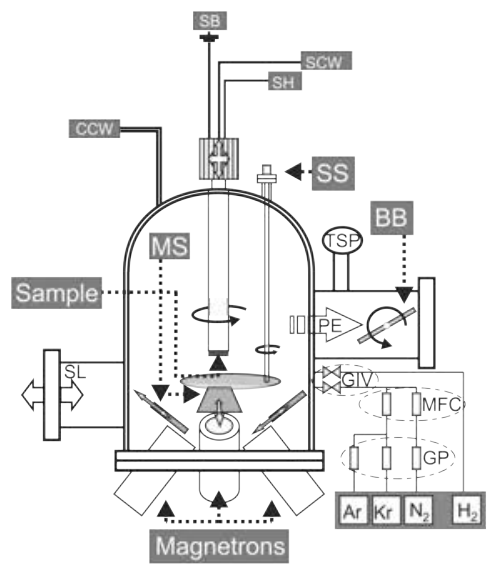

$\begin{array}{llll}\text { MFC } & \text { Mass flow controllers } & \text { GIV } & \text { Process gas inlet valve } \\ \text { GP } & \text { Gas Purifiers } & \text { SB } & \text { Sample bias } \\ \text { PE } & \text { Pump exhaust (Turbomolecular pump) } & \text { SCW } & \text { Sample cooling water } \\ \text { TSP } & \text { Titanium sublimation pump } & \text { CCW } & \text { Chamber cooling water } \\ \text { SL } & \text { Sample loading tube (towards transfer tube) } & \text { SH } & \text { Sample heating } \\ \text { MS } & \text { Magnetron sliding shutters } & \text { TR } & \text { Trolley rail for sample mounting } \\ \text { SS } & \text { Sample rotating shutter } & \text { BB } & \text { Butterfly baffle }\end{array}$

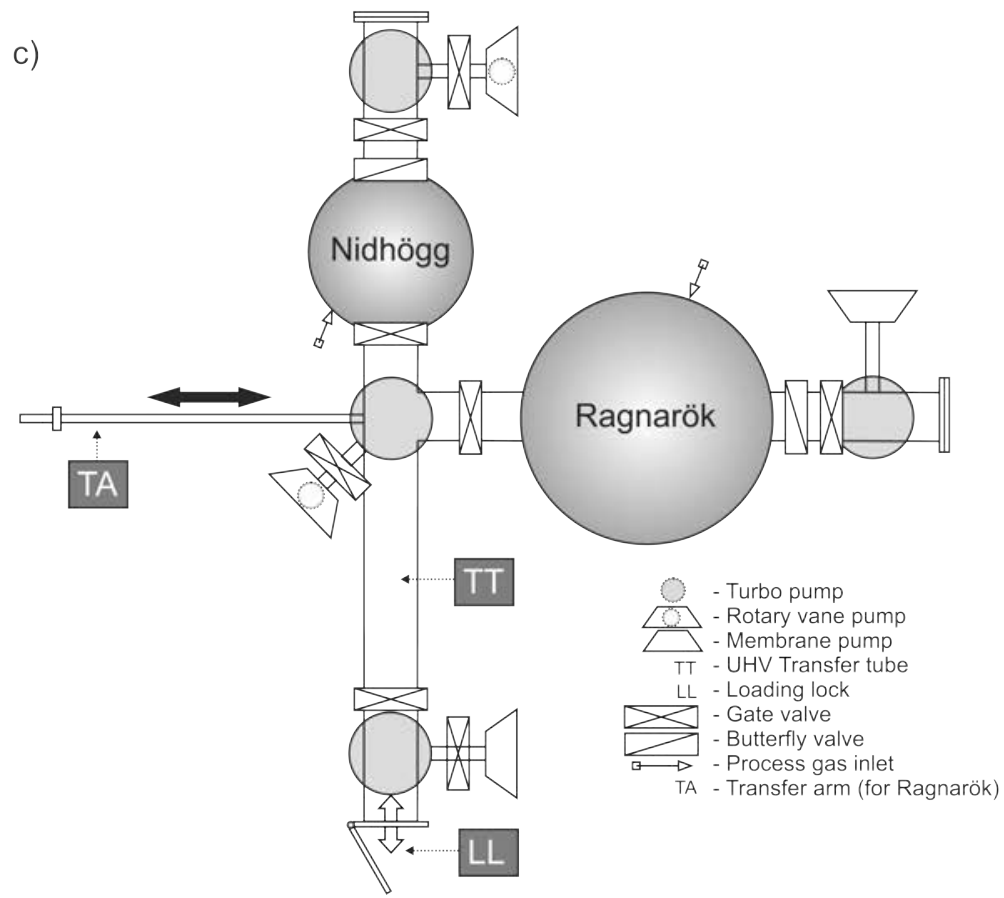

Figure 4.8: Illustration of the reaction chamber (a) Nidhögg and (b) Ragnarök (both in side view) together with (c) a top view illustration of both reactors with load lock and transfer tube included. 


\subsubsection{InAlN/GaN/InAlN heterostructure growth}

As discussed in Chapter 2, InAlN with an indium content of around $18 \%$ is lattice-matched to GaN according to Vegard's law. During this work, reactive DC-magnetron sputtering was employed to grow InAlN and InAlN/GaN/InAlN heterostructure. The long-term aim was to fabricate InAlN/GaN/InAlN QW structures to act as the inorganic component in hybrid structures. QW structures were fabricated, however, they were not of sufficient quality to be used as components in hybrid structures. The work was built on the knowledge of T. Seppänen ${ }^{81}$ for growing InAlN films and M. Junaid ${ }^{12}$ for growing GaN films. Both InAlN and GaN thin films has been grown from pure metallic targets. A systematic study of growth of InAlN and GaN on sapphire(0001) and InAlN/sapphire(0001) substrate, respectively, was performed and table 4.2 and 4.3 respectively, shows the optimized growth parameters as determined by CL, symmetric $\theta-2 \theta$ scans and how smooth the film appeared in top view SEM

Table 4.2: Suggested deposition parameters for InAlN on sapphire(0001) substrates.

\begin{tabular}{ll|lll|l|l}
\hline \multicolumn{6}{l}{ Target power } & \multicolumn{7}{c}{ Gas pressure } \\
\hline $\mathrm{Al}$ & $\mathrm{In}$ & $\mathrm{p}_{\mathrm{Ar}}$ & $\mathrm{p}_{\mathrm{N}_{2}}$ & $\mathrm{p}_{\text {tot }}$ & Temperature & $\begin{array}{l}\text { Bias } \\
{[\mathrm{W}]}\end{array}$ \\
{$[\mathrm{W}]$} & {$[\mathrm{mtorr}]$} & {$[\mathrm{mtorr}]$} & {$[\mathrm{mtorr}]$} & {$\left[{ }^{\circ} \mathrm{C}\right]$} & {$[\mathrm{V}]$} \\
\hline 350 & 10 & 0 & 5 & 5 & 700 & -30
\end{tabular}

Table 4.3: Suggested deposition parameters for GaN on InAlN.

\begin{tabular}{l|lll|l|l}
\hline Target power & \multicolumn{7}{c}{ Gas pressure } \\
\hline $\mathrm{Ga}$ & $\mathrm{p}_{\mathrm{Ar}}$ & $\mathrm{p}_{\mathrm{N}_{2}}$ & $\mathrm{p}_{\text {tot }}$ & Temperature & $\begin{array}{l}\text { Bias } \\
{[\mathrm{W}]}\end{array}$ \\
{$[$ mtorr $]$} & {$[\mathrm{mtorr}]$} & {$[\mathrm{mtorr}]$} & {$\left[{ }^{\circ} \mathrm{C}\right]$} & {$[\mathrm{V}]$} \\
\hline 10 & 2 & 2.5 & 4.5 & 700 & 0
\end{tabular}

By growing an additional layer of InAlN on an optimized GaN/InAlN/ sapphire(0001) substrate, it was observed by cross-section SEM that structural defects having a black drop-shape where formed close to the top InAlN/GaN interface (see figure 4.9). They were occurring in a vast number of samples grown with different parameters. However, it was found that by 
growing the top InAlN film using the parameters of table 4.2 at a considerably lower temperature $\left(25^{\circ} \mathrm{C}\right)$ we obtained a better crystal structure in the top InAlN/GaN interface as well as the InAlN film. This is the topic of Paper VI

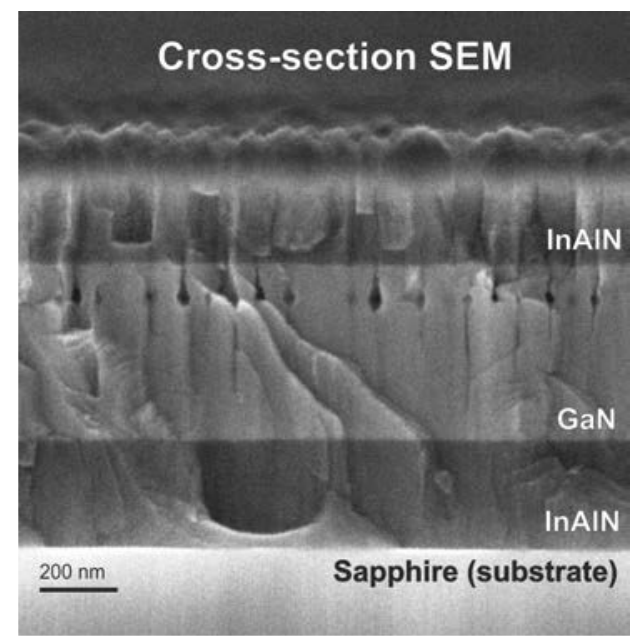

Figure 4.9: Typical sample containing clear InAlGaN inclusions close to the top InAlN/GaN interface. The mechanism of formation is suggested and further discussed in Paper VI.

\subsection{Metal-organic chemical vapor deposition}

Metal-organic chemical vapor deposition (MOCVD), is a method of chemical synthesis of thin films using metal-organic gaseous reagents. These reagents are called precursors. CVD is not a line of sight technique compared to, for example, sputter deposition. CVD can therefore be used to coat much more complex surfaces while achieving a more uniform thickness. CVD have a long tradition within the fabrication of photonic and electronic device structures since great control of the deposition is possible ${ }^{65,82}$. CVD process can be considered as a series of steps, illustrated in figure 4.10. First there is a transport of precursors into the reactor, then the following processes can be mentioned: diffusion or convection of precursors through the boundary layer, possible gas phase reaction, adsorption of the precursors, surface diffusion, surface chemical reaction, desorption of adsorbed precursors, desorption of reaction by-products and mass transport of by-products out of the chamber. 


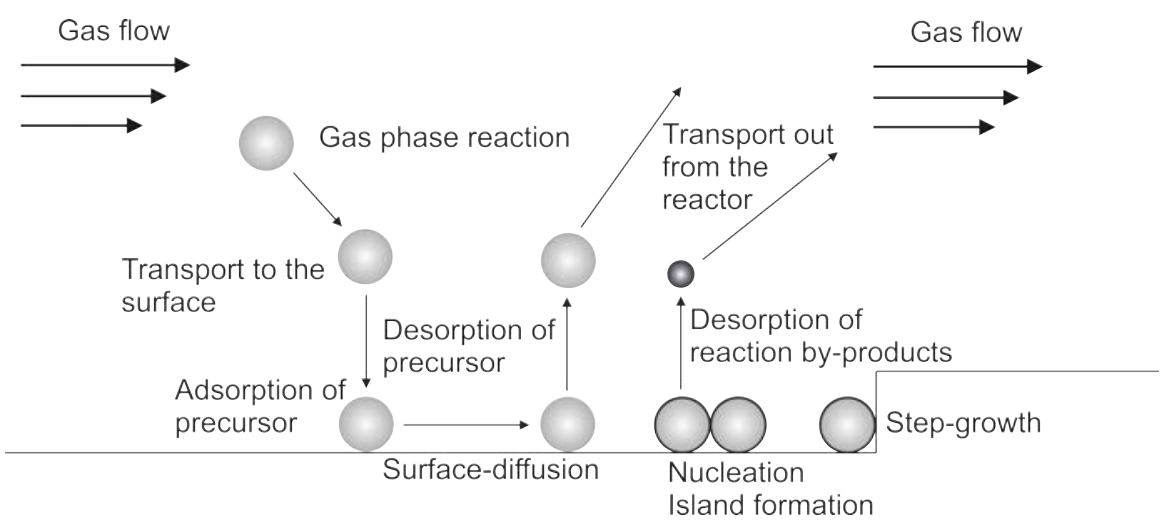

Figure 4.10: Illustration of the CVD process on precursor level near substrate surface.

The requirements for a "good" precursor are:

1. High volatility

2. High purity

3. Be non-toxic

4. Be available at low cost with consistent purity

5. Have good thermal stability during evaporation and transport into the reactor

6. Clean decomposition

7. Give non-hazardous by-products

Usually, not all of these requirements can be met. Volatility is one of the top priorities. Therefore, ligands that form hydrogen bonds, or strong dipole-dipole or Van-der-Waals interactions should be reconsidered ${ }^{83}$. There are two main choices when it comes to types of precursors; single source precursors or combined multiple precursors. The single source precursor contains all the elements desirable in the film in the form of one single molecule. This requires a higher planning of chemistry to make sure that the composition is also reflected in the precursor. The different bonds within the molecule must reflect the desired film. Some bonds are supposed to be in the film and have to be stronger, while some weaker bonds are supposed to break to release the supporting backbone of the precursor. Besides being more 
chemically hard to produce they also generally suffer from high molecular weight which gives them less volatility. However, when done correctly, the single source precursor has a clear advantage, because of a much better reproducibility can be achieved compared to the case of multiple sources where fluctuations in flow can cause fluctuations in stoichiometry ${ }^{82}$. For group III-nitride growth with MOCVD, the following typical main precursors are usually used: trimethyl-gallium, trimethyl-aluminum and trimethyl-indium. Ammonia is used as the source of nitrogen and $\mathrm{H}_{2}$ or $\mathrm{N}_{2}$ can be used as carrier gas. Metal organic precursors are stored in bubblers connected to the gas system of the growth reactor. The process of decomposition inside a growth chamber can be complicated and include several steps, for example: trimethyl-gallium decomposes first to dimethyl-gallium and then monomethyl-gallium ${ }^{84,85}$.

\subsubsection{Hot wall vs cold wall}

A CVD reactor can be divided into two main types; hot wall or cold wall. In conventional CVD, heat is the driving force which initiates the reactions. In cold wall reactors the substrate has higher temperature than the surrounding wall. This will decrease the reaction rate on the chamber walls and increase the precursor efficiency and consequently also the deposition rate on the substrate compared to the hot wall reactors. In hot wall reactors the whole reactor chamber is heated. In this case, a more uniform temperature distribution across the substrate can be achieved. Temperature gradients and fluctuations across the substrate are undesirable since it cause fluctuations in reaction rates, diffusion rates, and are detrimental to overall control of the film. However, in hot wall reactors, the gas phase reactions occur over the entire chamber which makes the control of the precursors partial pressure more difficult ${ }^{83}$.

\subsubsection{Growth rate}

Growth rate, $k$, depend on temperature $T$ of the substrate and activation energy $E_{A}$ of the reaction according to the Arrhenius equation:

$$
k=A e^{-\left(E_{A} / R T\right)}
$$

Where $R$ is the gas constant, $A$ is the pre-exponential factor representing how often molecules collide in the proper orientation. Three regimes of growth rate can be distinguished depending on temperature. These regimes are illustrated in figure 4.11. At low temperatures we find a so called kinetically limited regime. The low temperature means that the available energies 
are too small for most precursors to overcome the activation energy of the surface reactions. In the intermediate temperature regime, the temperatures are sufficient for precursors to overcome the energy barrier of reaction once the species reach the surface. Reaching the surface, which is done by diffusion, is the limiting step. This temperature regime is considered preferable because it is the most stable regime in respect to temperature fluctuations. Also, the growth rate in this regime can be conveniently changed by adjusting the partial pressure of the precursors, which is called a feed-rate-limited process.

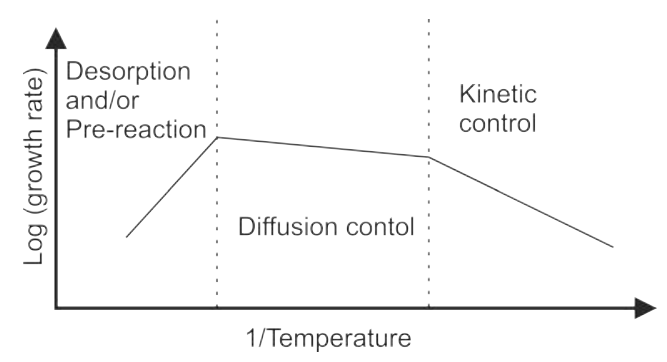

Figure 4.11: Illustration of how the growth rate (in a logarithmic scale) changes with reciprocal temperature (Arrhenius plot). Specific temperatures for each region are highly dependent on activation energy of the precursor.

At high temperatures all of the precursors decompose and react but the temperature is so high that the thermodynamics can change. Pre-reaction of the precursors may occur which is lowering the partial pressure and, additionally, the probability for desorption of species from the substrate increases. This will result in an overall lowering of the growth rate. 
CHAPTER 5

Characterization

\subsection{X-ray diffraction}

X-ray diffraction (XRD) was discovered by Laue et al. ${ }^{86}$ in 1912 . This technique is used for investigating crystal structures of materials. The diffraction occurs when electromagnetic radiation interact with a periodic structure and have comparable wavelength with the periodic arrangement (here the interatomic distance). In the case of crystals, the distance between atoms is in order of few angstroms, which corresponds to the wavelength of X-rays. As X-rays interacting with a material surface, three processes can occur; photoionization, Compton scattering or Thomson scattering. In Thomson scattering, which is used in XRD, the electromagnetic wave is elastically scattered by the electrons. Therefore the wavelength of the X-ray is preserved. Figure 5.1 illustrates schematically this scattering process.

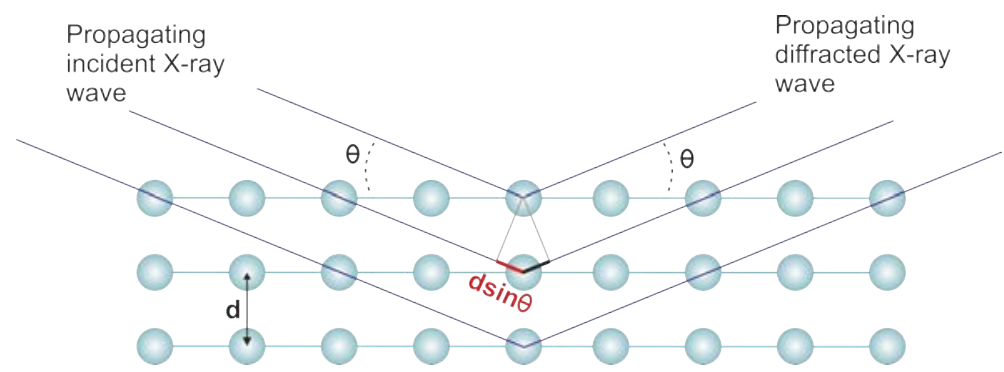

Figure 5.1: Illustration of X-ray interaction with a crystal structure. 
The scattering vector, (or reciprocal space vector) $\mathbf{Q}$ is defined as:

$$
\mathbf{Q}=\mathbf{K}-\mathbf{K}_{\mathbf{0}}
$$

Where $\mathbf{K}_{\mathbf{0}}$ and $\mathbf{K}$ are wave vectors of the incident and diffracted electromagnetic field with wavelength, $\lambda$. For elastic scattering:

$$
\left|\mathbf{K}_{\mathbf{0}}\right|=|\mathbf{K}|=\frac{2 \pi}{\lambda}
$$

Constructive interference occurs when ${ }^{87}$ :

$$
\left\{\begin{array}{l}
|\mathbf{Q}|=2\left|\mathbf{K}_{\mathbf{0}}\right| \sin \theta=\frac{4 \pi}{\lambda} \sin \theta \\
|\mathbf{Q}|=\frac{2 \pi}{d}
\end{array}\right.
$$

Where $d$ is the interplanar spacing. From this condition, we obtain Braggs law

$$
\lambda=2 d \cdot \sin \theta
$$

For a specific source, $\lambda$ is known, $\theta$ can be detected; thus, $d$ can be obtained. In order to model and understand a diffractogram, also a geometrical structure factor and an atomic form factor have to be considered.

In a $\theta-2 \theta$ the incident beam angle and the detection angle is simultaneously changed. Expected diffractogram peaks for powder samples van be found in reference data bases. Samples like thin films can exhibit specific preferred crystal alignment in relation to the incident beam and will therefore display peaks with a different intensity ratio compared to a powder sample. XRD is a technique that maps the reciprocal lattice points of the crystal structure. By performing a $\theta-2 \theta$ scan, the scan direction shown in figure $5.2 \mathrm{a}$ is perpendicular to the surface along the direction of the scattering vector. Also, a rocking curve scan ( $\omega$-scan) is illustrated in figure 5.2b. A quantitative estimation of the crystal quality can be done by determining the full width at half maximum (FWHM) of the obtained peak in $\omega$-scan. From reciprocal space maps, information such as the in-plane lattice parameters and film strain can be obtained and, therefore, XRD is a common powerful non-destructive technique to study structural crystal quality. 

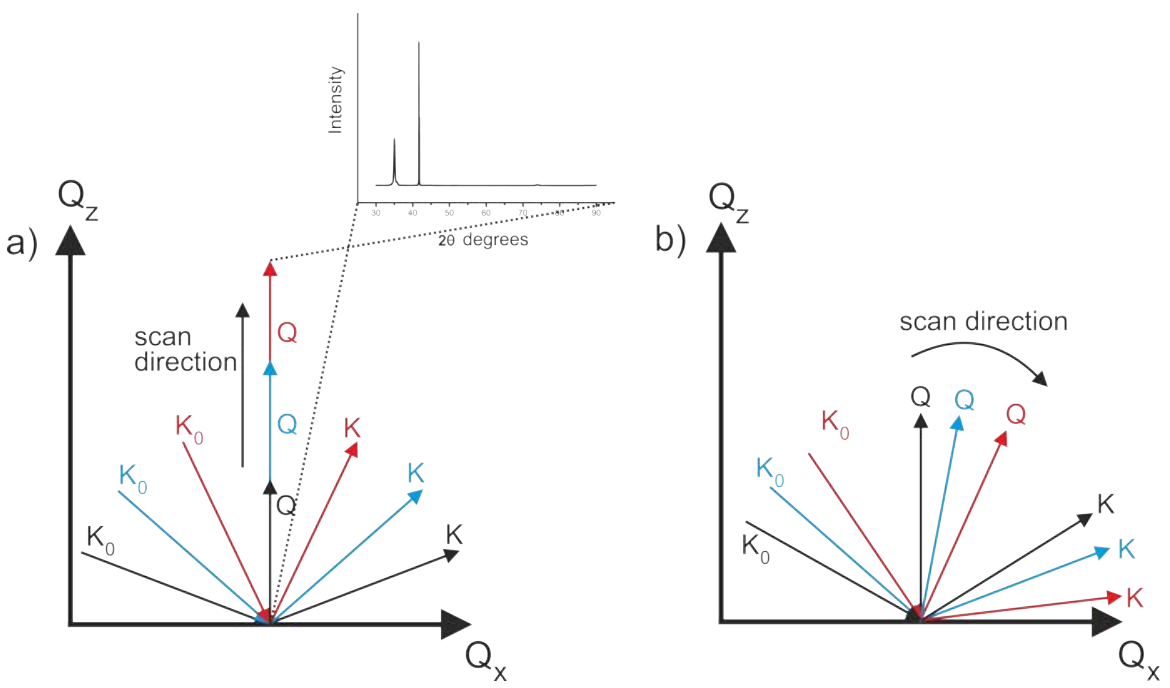

Figure 5.2: Illustration of scan direction in a) a $\theta-2 \theta$ scan and b) a rocking curve scan

\subsection{Scanning electron microscopy}

Scanning electron microscopy (SEM) is a widely used tool to examine microstructures and morphology since it can image much smaller features than using visible-light optical microscopy. SEM can resolve nanoscale details with high resolution, which depends on wavelength, $\lambda$, of the electron ${ }^{88}$ :

$$
\lambda=\frac{h}{\sqrt{2 m E}}
$$

Where, $h$, is Planck's constant, $E$ is the kinetic energy of the electrons, and $m$ is the electron mass. In case of SEM, typical energies of electrons in the beam are ranged between 0.5 and $40 \mathrm{keV}$ giving a wavelength of few $\mathrm{nm}$. Thus, compared with a visible-light (wavelength in the range of 400-700 nm) optical microscopy, the resolution of SEM is considerably better.

In SEM, when an electron beam irradiates the sample surface several processes occur, such as; produced X-rays, Auger electrons and cathodoluminescence. The excitation volume dependence on the material density and electron beam energy. Figure 5.3 illustrates up to which relative depth the different processes can be detected. By increasing the energy of the electrons, the excitation volume increases. 


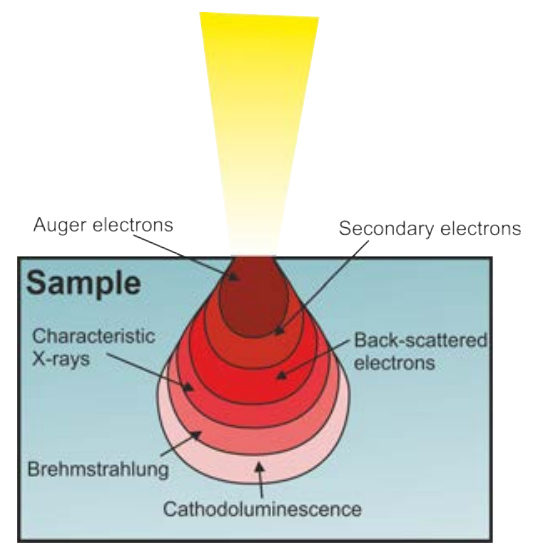

Figure 5.3: Schematic drawing of excitation volume and the regions from where each type of signal can be measured.

An impinging electron beam will create an electron surplus which will lead to a negative potential on the surface. The potential will start to deflect the electron beam and disturbing the image, i.e. the image will be drifting. Preferably the sample should be conductive and grounded to mitigate this effect. However, if the sample is a poor conductor, lowering the beam energy, beam current and careful grounding of the sample surface can be used to improve the quality of the image. To improve the grounding, samples can be coated by a thin conductive metal film (usually gold or platinum) before SEM study. The problem with coating is that the topology can be slightly altered.

A SEM is composed of an electron gun, condenser lenses, deflection coils, an objective lens, sample holder and detectors placed within a vacuum chamber. Our system is a LEO 1550 Gemini SEM with a field emission gun (FEG) as an electron source. One of the most important advantages with FEG is the superior brightness compared to a thermionic gun even at much lower acceleration voltages. Brightness is the current density per unit solid angle of the source. A high brightness means more electrons can be aimed at the sample so that more information can be obtained while maintaining the spot size of the beam ${ }^{88}$. A FEG creates electrons by applying several $\mathrm{kV}$ to a very thin tip to have it emit electrons. The LEO 1550 system has a so called Schottky FEG electron gun which means a heating current is also applied to enhance the emission. When electrons leave the gun they enter a set of electromagnetic lenses and the deflection coils. When the electrons pass through a magnetic field they experience a Lorentz force. As a result, the electron beam can be controlled and focused. The deflection coils create 
a magnetic field in order to steer the electron beam so that it can scan the surface. The objective lens is the lens situated between the deflection coils and the sample. This lens is responsible for focusing on the surface so that the impinging beam radius is small.

In SEM the secondary electrons or the back scattered electrons are detected to form an image. Since secondary electrons are electrons emitted from the outer shell of the material atoms they have low energies, so they will come from confined places close to the surface. This means that detecting secondary electrons will give a good topographical contrast. Electrons are scattered better by the heavier nuclei and, thus, the fraction of backscattered electrons increases with increasing atomic number of the elements. Therefore, a backscattered image give a compositional contrast and useful for differentiating different mineral phases. However, SEM images do not give elemental information of the sample.

\subsection{Transmission electron microscopy}

Transmission electron microscopy (TEM) was first developed in 1932 by Knoll and Ruska ${ }^{89}$. TEM is also an electron microscopy technique such as SEM. However, there are some significant differences. SEM is a technique that produces images from detecting secondary and back scattered electrons while TEM produce images from detecting transmitted electrons. Electrons need to be transmitted in order to reach the fluorescent screen or CCD below the sample. Therefore, TEM requires very thin samples transparent to electrons. This mean, that TEM is a destructive technique since the sample needs to be cut and polished to the proper thickness. Another difference is that TEM operates at much higher beam energies (100-300 $\mathrm{keV}$ ) which allows for higher spatial resolution (equation 5.5 still applies). In this thesis, samples were studied with a high resolution FEI Tecnai G2 200 keV FEG scanning electron microscope. Since TEM uses the information of transmitted electrons, both images and electron diffraction patterns similar to X-ray diffraction patterns can be produced. Being able to combine the high spatial resolution with information about the crystal structure makes TEM a very powerful characterization technique. 


\subsection{Cathodoluminescence}

Under electron beam irradiation, electrons of the material are excited to the conduction band and then they can recombine radiatively with holes emitting photons. The process is called cathodoluminescence (CL). In CL, one electron from the electron gun with the energy of several keV can create 1000 s of electron-hole pairs in contrast to photoluminescence, where one excitation photon results in formation of one electron-hole pair.

Our laboratory is equipped with a Gatan MonoCL4 ${ }^{\mathrm{TM}}$ CL system combined with an SEM (figure 5.4). It employs a Czerny-Turner type monochromator with a focal length of $300 \mathrm{~mm}$. There are a number of diffraction gratings blazed at different wavelength and allowing different resolution. In this work two diffraction gratings with 150 and 1200 lines/mm were used.

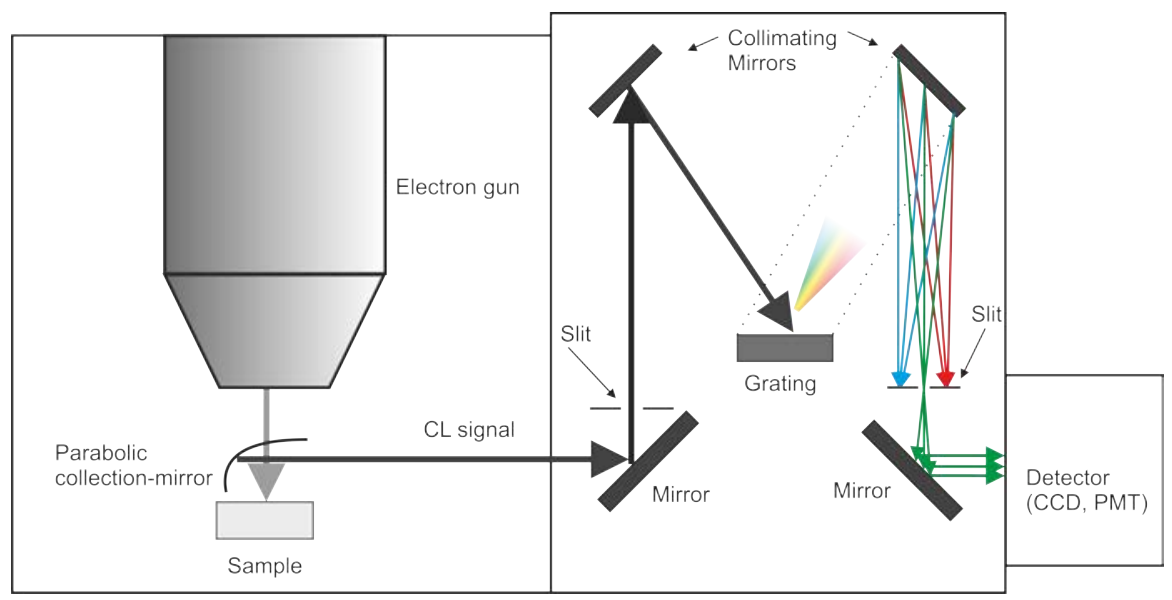

Figure 5.4: A simple illustration of the CL setup used during this work

CL is a useful technique to investigate light emission from semiconductors or some dielectrics. The energy of the electron beam is higher than the photon energies for most of the lasers used in photoluminescence, which allows excitation of materials with a wide band gap and even insulators. Another advantage with CL combined with SEM is a high spatial resolution of the same order as in SEM or as in TEM, when CL is combined with TEM. SEM and CL images can be detected simultaneously allowing direct correlation between CL intensity contrast and SEM image.

Since different defects, dopants and inclusions of different crystal phases have unique optical signatures, CL can be used for identification of radiative centers. As an example, figure 5.5 shows a top-view SEM image with a cor- 
responding panchromatic CL image taken for one of the III-nitrides samples grown during this work. The shown region reveals a typical morphological defect, named "flower-like" formations or "roses". The bright contrast in CL map corresponds to higher emission intensity, thus, attributing the most CL signal to the "roses". By focusing the electron beam on specific points of the flower-like formation one could resolve different CL-signals from different regions of the rose. It is also possible to obtain several monochromatic images in order to reveal which part of the structure that is responsible for the different luminescence. Because of the relatively large excitation volume in SEM/CL shown in figure 5.3, additional information from the deeper layers or substrate can also be obtained in CL.

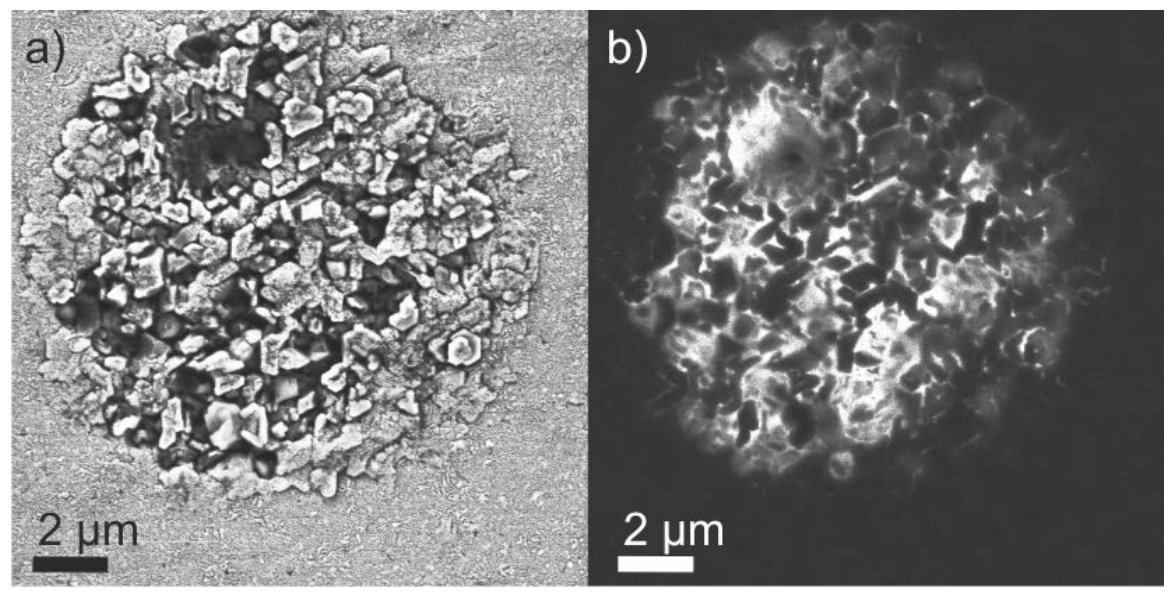

Figure 5.5: Room temperature top-view SEM image (a) with corresponding panchromatic CL image (b) of a typical defect region discovered in several samples while growing InAlN/GaN heterostructures. CL can give valuable information about the crystal structure at very high resolution. (images has been given increased contrast in image post-processing)

Our CL setup has the possibility of employing a liquid He-cooled cryostage for sample mounting. This allows for low temperature measurements, which is important for analyzing semiconductors, where near band gap emission can give information about electronic properties including shallow dopant levels with activation energies on the order of tens of meV or less, which will be thermalized at room temperature. Also, at higher temperatures, contribution of non-radiative recombination increases which reduces emission intensity, while the peak broadening increases due to thermalization and phonon-interaction ${ }^{36,90}$. 


\subsection{Photoluminescence}

In photoluminescence (PL), the excitation is done using a light source such as a laser, LED or lamp. PL has some advantages compared to CL, for example allowing resonance excitation of levels inside the band gap ${ }^{91}$. A schematic drawing of PL setup is displayed in figure 5.6. A continuous wave (CW) diode-pumped solid-state $\mathrm{Nd}: \mathrm{YVO}_{4}$ laser (Verdi) with $18 \mathrm{~W}$ output power in the second harmonics (532 nm) was used to pump a Ti:sapphire $(\sim 800 \mathrm{~nm})$ femtosecond solid state laser. The pulse frequency of $75 \mathrm{MHz}$ was regulated through Kerr lens mode-locking. A tripler was employed to obtain the third harmonics $(266 \mathrm{~nm})$ pulsed laser which corresponds to a photon energy of $4.65 \mathrm{eV}$ (i.e. above $\mathrm{GaN}$ band gap).

The laser illuminates the sample and the emission from the sample is collected and focused by lenses into a monochromator. In order to study the PL at different temperatures, the samples were cooled using liquid $\mathrm{He}$ in a cryostat supplied with heater. Thus, temperature-dependent PL measurement can be performed from $2 \mathrm{~K}$ to room temperature.

\section{TRPL set-up}

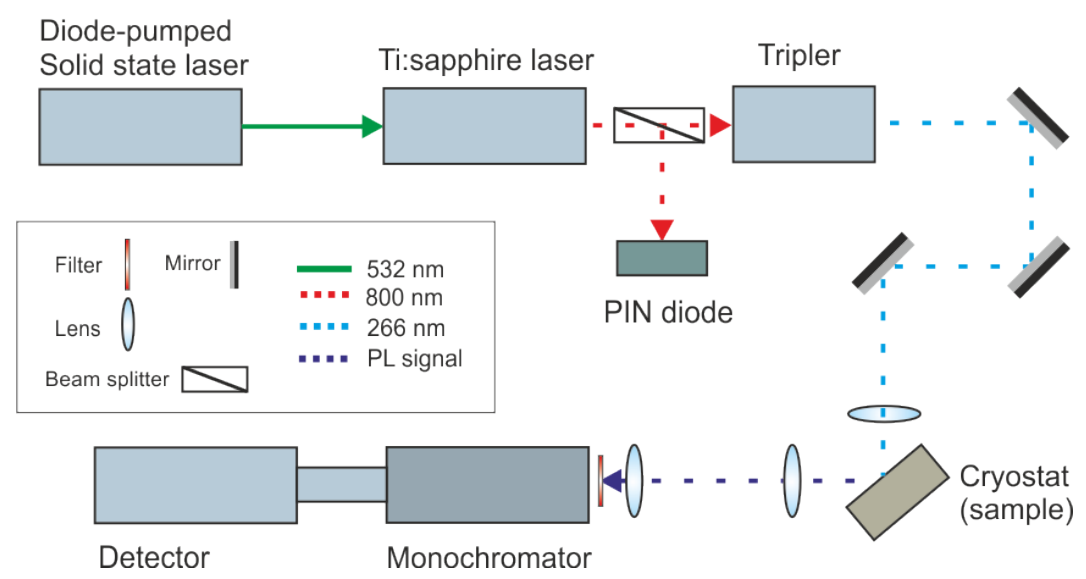

Figure 5.6: Illustration of the TRPL setup used in Paper I and II

\subsubsection{Time-resolved photoluminescence (TRPL)}

Using time-resolved PL (TRPL) the recombination dynamics of different transitions is measured and a minority carrier lifetime can be extracted. TRPL was excited by a femtosecond pulsed Ti:sapphire laser and a streakcamera was used for detection. The light entering the streak camera pro- 
duces electrons when impinging on a photo-cathode surface. The electrons are accelerated through a pair of electrodes that slightly deflect them with an applied voltage that varies smoothly with time. After this, the electrons impinge on a thin phosphor screen that will emit light. The light is collected by the CCD placed behind the screen. A typical time-resolved image is shown in figure $5.7 \mathrm{a}$ with a time-integrated spectrum of the same sample in figure 5.7b. PL transient curves taken at energies $\sim 3.42 \mathrm{eV}$ and $\sim 3.47$ $\mathrm{eV}$, respectively, are illustrated in figure 5.7c. Obviously, those transitions have different temporal behavior and, thus, have different origin.
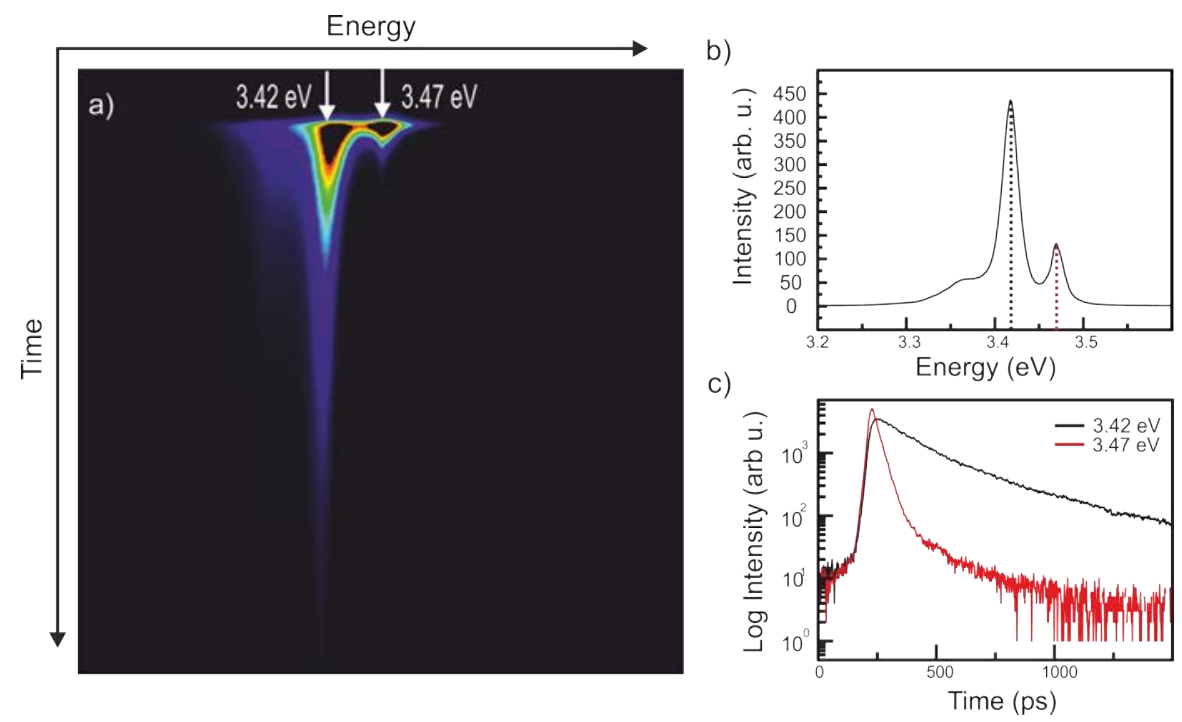

Figure 5.7: Measurement data obtained from a typical TRPL measurement during this work. (a) Display the streak camera image with time vs energy and color-coded intensity and $3.42 \mathrm{eV}$ and $3.47 \mathrm{eV}$ transitions highlighted. (b) Also shown, a time-integrated spectrum of the same data shown in (a) and (c) are the transient curves of the $3.42 \mathrm{eV}$ and $3.47 \mathrm{eV}$ transitions respectively.

\subsubsection{Micro time-resolved photoluminescence ( $\mu$-TRPL)}

To study emission properties of nanostructures we have performed $\mu$-TRPL combining advantages of optical microscope spatial resolution with the time resolution of the TRPL technique. The laser beam could be focused into a spot of $\sim 1 \mu \mathrm{m}$ in diameter on the sample using an objective reflective lens. The sample was placed inside the liquid-He-cooled flow cryostat equipped 
with a X-Y translation stage. Though the resolution in $\mu$-TRPL is less compared to CL, it enables to study separate features with the size of $\sim 1 \mu \mathrm{m}$ or single nanostructures with even smaller dimensions. This setup was used for experiments described in Paper IV and V. 


\section{CHAPTER 6}

\section{Scientific Contriubtions}

\subsection{Paper I \\ Dynamic properties of excitons in $\mathrm{ZnO} / \mathrm{AlGaN} / \mathrm{GaN}$ hybrid nanostructures}

In paper I, hybrid structures based on AlGaN/GaN quantum well (QW) structures and colloidal $\mathrm{ZnO}$ nanocrystals (NC) have been studied by timeresolved photoluminescence (TRPL) measurements in the temperature range 5-300 K. The ZnO nanocrystals were deposited on top of the QW structures having different cap layer thicknesses between 3 and $9 \mathrm{~nm}$. It was shown that the recombination dynamics of excitons confined to a GaN QW can change in presence of $\mathrm{ZnO}$ nanocrystals provided that the spatial distance between the QW and NCs is small enough. It is suggested that non-radiative resonance energy transfer (NRET) from the QW excitons to the $\mathrm{ZnO} \mathrm{NC}$ and a variation of the surface potential can both influence the $\mathrm{QW}$ exciton lifetime in the hybrids. In the hybrid with a $9 \mathrm{~nm} \mathrm{QW}-\mathrm{NC}$ distance no significant change in exciton dynamics could be observed. 


\subsection{Paper II}

Time-resolved photoluminescence properties of hybrids based on inorganic AlGaN/GaN quantum wells and colloidal $\mathrm{ZnO}$ nanocrystals

In paper II, pumping efficiency and degradation effects due to ageing is reported for a hybrid structure consisting of an AlGaN/GaN quantum well (QW) with a $3 \mathrm{~nm}$ cap layer coated with colloidal $\mathrm{ZnO}$ nanocrystals (NCs). For the study, TRPL was used. Assuming that one of the recombination mechanisms is non-radiative resonant energy transfer (NRET) between the QW and the $\mathrm{ZnO} \mathrm{NCs}$, the maximum pumping efficiency was estimated to be $42 \%$ at $60 \mathrm{~K}$. After ageing of the structure for $\sim 1$ year in ambient temperature and pressure, it was observed that the recombination time had increased to a similar value observed in QW without NCs. We suggest that the increase of recombination time is associated with a degradation of the interface between the QW and NCs.

\subsection{Paper III \\ Stacking fault related luminescence in GaN nanorods}

In this paper, we have studied structural and optical properties of GaN NRs grown on $\mathrm{Si}(111)$ substrates by using a liquid Ga target in a DC magnetron sputtering system. Structural properties has been studied by X-ray diffraction and transmission electron microscopy (TEM). TEM images reveal a number of basal plane stacking faults (SF) having a characteristic signature at $3.42 \mathrm{eV}$ in luminescence spectra at $5 \mathrm{~K}$. Temperature dependent TRPL show that the SF related emission is stable even at enhanced temperature, exhibiting a rather fast dynamics, which is typical for type I QWs. However, a basal plane SF in wurtzite GaN forms a type II QW with practically no confinement for holes. It is suggested in accordance with TEM results that the SFs form a regular structure similar to multiple quantum wells (MQW) where a more efficient confinement for carriers can be achieved. 


\title{
6.4 Paper IV
}

\author{
Polarization of stacking fault related luminescence in GaN \\ nanorods
}

In paper IV, optical properties, especially polarization response of GaN NRs have been studied. Single NRs either with or without basal plane stacking faults (SF) were allowed to be distinguished and studied using micro photoluminescence from $5 \mathrm{~K}$ to room temperature. We show that the $\mathrm{SF}$ related emission demonstrates a strong linear polarization perpendicular to the NR axis at low temperatures. The GaN exciton line at $\sim 3.48 \mathrm{eV}$, in contrast, demonstrate no polarization even at low temperatures. A maximum degree of polarization of $48 \%$ is reported for SF related emission of $\sim 3.43 \mathrm{eV}$ at 5 K. At room temperature, the two peaks are indistinguishable and the rod displays no polarization. Similar measurements were performed in top-view geometry. No preferential polarization has been observed in this case for either SF emission or DBE line. The results also correlates well with theoretical predictions of bonding anisotropies within the wurtzite-zinkblende interface being responsible for the polarized emission observed.

\subsection{Paper V \\ Near band gap luminescence in hybrid organic-inorganic structures based on sputtered GaN nanorods}

In paper $\mathrm{V}$, hybrid structures based on GaN NRs and the green emitting polyfluorene F8BT have been studied using $\mu \mathrm{TRPL}$ in the temperature range $5 \mathrm{~K}$ to room temperature. F8BT dissolved in chloroform $(4 \mathrm{~g} / \mathrm{l})$ was deposited on the as-grown GaN NR samples using spin coating method. Measurements were performed before and after F8BT deposition. It was shown that the recombination times of charge carriers confined to the SFs decrease in the presence of F8BT; while the GaN exciton recombination times were either unaffected or increased depending on excitation power. It is suggested that a NRET mechanism from the SFs to F8BT influence the recombination time. Electronic states within the SFs are expected to couple more strongly with the electronic states of F8BT compared to donor-bound or free excitons within the NR. 


\subsection{Paper VI}

InAlGaN regions and flower-like formations in GaN films from DC-magnetron sputtered $\operatorname{In}_{x} \mathrm{Al}_{1-\mathrm{x}} \mathrm{N} / \mathrm{GaN}$ heterostructures

In this paper, lattice-matched InAlN/GaN samples grown by DC magnetron sputtering on sapphire(0002) was optically and structurally studied. It was found using scanning electron microscopy (SEM) and TEM that growing the top InAlN film at deposition temperatures of $700{ }^{\circ} \mathrm{C}$ was accompanied with structural defects along the top InAlN/GaN interface. The structural defects were found to be regions of a quarternary InAlGaN alloy. It was further found that growing the top InAlN film at room temperature $(\sim 25$ ${ }^{\circ} \mathrm{C}$ ) allowed for an improved interface quality and a mechanism of formation of the defects was suggested. In addition to this, observations of optically active flower-like defect formation was reported. These were studied using top view and cross-sectional cathodoluminescence (CL) measurements. Emission peaks at $3.34 \mathrm{eV}$ and $3.56 \mathrm{eV}$ with a FWHM of $\sim 33-40 \mathrm{meV}$ and characteristic LO phonon replicas were observed. 
Bibliography

1. W. Utsumi et al., Nature materials 2, 735-8 (2003).

2. X. H. Wu et al., Applied Physics Letters 68, 1371-1373 (1996).

3. B. Heying et al., Journal of Applied Physics 88, 1855-1860 (2000).

4. C. Hemmingsson, G. Pozina, Journal of Crystal Growth 366, $61-66$ (2013).

5. C. Hemmingsson et al., Superlattices and Microstructures 40, 205 213 (2006).

6. C. Hemmingsson et al., Journal of Crystal Growth 311, $292-297$ (2009).

7. R. Madar, G. Jacob, J. Hallais, R. Fruchart, Journal of Crystal Growth 31, $197-203$ (1975).

8. S. Porowski, Journal of Crystal Growth 166, 583 -589 (1996).

9. H. Yamane, M. Shimada, S. J. Clarke, F. J. DiSalvo, Chemistry of Materials 9, 413-416 (1997).

10. M. Yusuke, I. Mamoru, M. Mihoko, Y. Masashi, Journal of Solid State Science and Technology 2, N3068-N3071 (2013).

11. B. Wang, M. J. Callahan, Crystal Growth \& Design 6, 1227-1246 (2006).

12. M. Junaid, Magnetron Sputter Epitaxy of GaN, ISBN: 9789175197821.

13. B.-l. Li, H.-z. Zhuang, C.-s. Xue, S.-y. Zhang, Superlattices and Microstructures 43, 262-267 (2008). 
14. Z. Dong et al., Physica E: Low-dimensional Systems and Nanostructures 27, 32-37 (2005).

15. H. Amano, N. Sawaki, I. Akasaki, Y. Toyoda, Applied Physics Letters 48, 353 (1986).

16. M. Iwaya et al., Japanese journal of applied physics 37, L316-L318 (1998).

17. V. Narayanan, K. Lorenz, W. Kim, S. Mahajan, Applied Physics Letters 78, 1544 (2001).

18. Q. Dai et al., Applied Physics Letters 94, 111109 (2009).

19. D. Zubia, S. D. Hersee, Journal of Applied Physics 85 (1999).

20. W. Bergbauer et al., Nanotechnology 21, 305201 (2010).

21. K. Starosta, Physica status solidi (a) 68, 55-57 (1981).

22. C.-L. Hsiao et al., Thin Solid Films 524, 113-120 (2012).

23. C. R. Belton et al., Journal of Physics D: Applied Physics 41, 094006 (2008).

24. U. Mitschke, P. Bauerle, Journal of Materials Chemistry 10, 14711507 ( 7 2000).

25. H. V. Demir et al., Nano Today 6, 632-647 (2011).

26. P. L. Burn et al., Nature 356, 47-49 (1992).

27. G. Heliotis et al., Applied Physics Letters 87, 103505 (2005).

28. M. Wu et al., Optics Express 17, 16436-16443 (2009).

29. V. W. L. Chin, T. L. Tansley, T. Osotchan, Journal of Applied Physics 75, 7365 (1994).

30. A. J. Steckl, J. Heikenfeld, S. C. Allen, S. Member, Journal of display technology 1, 157-166 (2005).

31. F. Hide, P. Kozodoy, S. P. DenBaars, A. J. Heeger, Applied Physics Letters 70, 2664 (1997).

32. E. Gu et al., Applied Physics Letters 90, 2005-2008 (2007).

33. G. Itskos et al., Nanotechnology 20, 275207 (2009).

34. M. Achermann et al., en, Nature 429, 642-646 (2004).

35. D. Basko, G. C. L. Rocca, F. Bassani, V. M. Agranovich, European Physical Journal B 362, 353-362 (1999).

36. M. Grundmann, The physics of semiconductors (Springer-Verlag, Berlin, 2nd, 2010), ISBN: 978-3-642-13883-6. 
37. S. Strite, Journal of Vacuum Science \& Technology B. 10, 1237 (1992).

38. U. Müller, Inorganic structural chemistry (Wiley-VCH Verlag Gmbh \& Co. KGaA, Weinheim, 2nd, 2007), ISBN: 978-0-470-01865-1.

39. P. Waltereit et al., Nature 406, 865-868 (2000).

40. I. Vurgaftman, J. R. Meyer, Journal of Applied Physics 94, 3675 (2003).

41. C. Stampfl, C. Van de Walle, Physical Review B 57, R15052-R15055 (1998).

42. G. Salviati et al., Physica status solidi (a) 171, 325 (1999).

43. S. Khromov et al., Physical Review B - Condensed Matter and Materials Physics 84, 3-8 (2011).

44. I. Vurgaftman, J. R. Meyer, L. R. Ram-Mohan, Journal of Applied Physics 89, 5815 (2001).

45. R. Butté et al., Journal of Physics D: Applied Physics 40, 6328 (2007).

46. B. P. Burton, a. van de Walle, U. Kattner, Journal of Applied Physics 100, 113528 (2006).

47. G. Zhao et al., Scientific Reports 6, 26600 (2016).

48. C. Edmunds et al., Physical Review B 88, 235306, ISSN: 1098-0121 (2013).

49. F. Ponce, D. Bour, Nature 386, 351-359 (1997).

50. C. E. Dreyer, A. Janotti, C. G. Van De Walle, Applied Physics Letters 102, 1-4, ISSN: 00036951 (2013).

51. S. Albert-Seifried et al., Physical Review Letters 105, 195501 (2010).

52. S. Davydov, Physics of the Solid State 51, 1231-1235 (2009).

53. S. Blumstengel, S. Sadofev, C. Xu, J. Puls, F. Henneberger, Physical Review Letters 97, 237401 (2006).

54. S. Schulz, E. P. O’Reilly, physica status solidi (c) 7, 1900-1902 (2010).

55. T. Förster, Die naturwisseshaften 6, 166-175 (1946).

56. T. Förster, Annalen der physik 6, 55-75 (1948).

57. T. Förster, Zeitschrift für naturforschung 4a, 321-327 (1949).

58. V. M. Agranovich, Y. N. Gartstein, M Litinskaya, Chemical Reviews 111, 5179-5214 (2011).

59. B. S. Blumstengel, S Sadofev, J Puls, F Henneberger, Advanced Materials, 4850-4853 (2009). 
60. J. J. Rindermann et al., Physical Review Letters 107, 236805 (2011).

61. H. Singh, B. Bagchi, Current science 89, 1710-1719 (2005).

62. J. Hill et al., Physical Review B 69, 041303 (2004).

63. V. M. Agranovich, G. C. La Rocca, F. Bassani, Journal of Experimental and Theoretical Physics Letters 66, 748-751 (1997).

64. T. E. Kazior, Philosophical Transactions of the Royal Society of London A: Mathematical, Physical and Engineering Sciences 372 (2014).

65. M. Ohring, Materials science of thin films: Deposition \& structure (Elsevier (Singapore) Pte Ltd., 2nd, 2006), ISBN: 0-12-524975-6.

66. G. Aylward, T. Findlay, SI chemical data (John Wiley \& Sons Australia., Sidney and Melbourne, fifth edit, 2002), ISBN: 9780470800447.

67. J. F. O'Hanlon, A User's Guide to Vacuum Technology (John Wiley \& Sons, Inc., 3rd, 2003), ISBN: 0-471-27052-0.

68. M. M. Jakas, Philosophical transactions. Series A, Mathematical, physical, and engineering sciences 362, 139-56 (2004).

69. H. Oechsner, Applied Physics 8, 185-198 (1975).

70. D. M. Mattox, Society of vacuum coaters, 2003, http://www. svc . org/Historyof VacuumCoating/History - of - Vacuum-Coating . cfm (visited on $09 / 15 / 2016$ ).

71. L. Tonks, I. Langmuir, Physical Review 33, 195-211 (1929).

72. I. Petrov, P. Barna, L. Hultman, J. Greene, Journal of Vacuum Science \& Technology A: Vacuum, Surfaces, and Films 21, S117 (2003).

73. A. Anders, Thin Solid Films 518, 4087-4090 (2010).

74. J. A. Thornton, Journal of Vacuum Science and Technology 11, 666 (1974).

75. J. A. Thornton, Journal of Vacuum Science \& Technology A: Vacuum, Surfaces, and Films 4, 3059 (1986).

76. D. Depla, Magnetrons, reactive gases and sputtering (1st, 2013), ISBN: 978-1-304-34781-7.

77. S. Berg, T. Nyberg, Thin Solid Films 476, 215-230 (2005).

78. P. Kelly, R. Arnell, Vacuum 56, 159-172 (2000).

79. B. Wolf, Handbook of Ion Sources (CRC Press, Inc, 1995), ISBN: 08493-2502-1.

80. C.-L. Hsiao et al., Nano Letters 15, 294-300 (2015). 
81. T. Seppänen, Growth and Characterization of Metastable Wide bandgap $A l(1-\mathrm{x}) \operatorname{In}(\mathrm{x}) \mathrm{N}$ epilayers, ISBN: 91-85523-58-5.

82. A. C. Jones, M. L. Hitchman, Chemical Vapour Deposition - Precursors, Processes and Applications (Royal Society of Chemistry, Cambridge, 2008), ISBN: 978-0-85404-465-8.

83. U. Schubert, N. Hüsing, Syhtesis of Inorganic Materials (Wiley-VCH Verlag Gmbh \& Co. KGaA, Weinheim, Second rev, 2005), ISBN: 3-52731037-1.

84. A. Hirako, S. Koiso, K. Ohkawa, Physica Status Solidi (a) 203, 17161719 (2006).

85. Q. Chen, P. D. Dapkus, Journal of electrochemical society 138, 28212826 (1991).

86. G. Hildebrandt, Crystal Research and Technology 28 (1993).

87. M. Birkholz, Thin film analysis by X-ray scattering (Wiley-VCH Verlag Gmbh \& Co. KGaA, Weinheim, 2006), ISBN: 3-527-31052-5.

88. D. B. Williams, C. B. Carter, in Transmission electron microscopy (Springer Science+Buissnes Media, LLC, New York, 2nd, 1996), ISBN: 978-0-387-76502-0.

89. Ernst Ruska - Biographical, Nobelprize.org. Nobel Media AB 2014, http: //www . nobelprize.org/nobel_prizes/physics/laureates / 1986/ruska-bio.html (visited on 09/15/2016).

90. J. V. D. Veliadis, J. B. Khurgin, Y. J. Ding, A. G. Cui, D. S. Katzer, Physical Review B 50, 4463-4469 (1994).

91. A. Meeder et al., Thin Solid Films 404, 495-499 (2002). 


\section{Papers}

The articles associated with this thesis have been removed for copyright reasons. For more details about these see:

http://urn.kb.se/resolve?urn=urn:nbn:se:liu:diva-132267 